University of South Florida

DIGITAL COMMONS

Digital Commons @ University of

@ UNIVERSITY OF SOUTH FLORIDA

South Florida

School of Geosciences Faculty and Staff

Publications

2-1991

\title{
First Epoch Geodetic Measurements with the Global Positioning System Across the Northern Caribbean Plate Boundary Zone
}

Timothy H. Dixon

California Institute of Technology, thd@usf.edu

G. Gonzalez

California Institute of Technology

S. M. Lichten

California Institute of Technology

E. Katsigris

California Institute of Technology

Follow this and additional works at: https://digitalcommons.usf.edu/geo_facpub

Part of the Earth Sciences Commons

\section{Scholar Commons Citation}

Dixon, Timothy H.; Gonzalez, G.; Lichten, S. M.; and Katsigris, E., "First Epoch Geodetic Measurements with the Global Positioning System Across the Northern Caribbean Plate Boundary Zone" (1991). School of Geosciences Faculty and Staff Publications. 502.

https://digitalcommons.usf.edu/geo_facpub/502

This Article is brought to you for free and open access by the School of Geosciences at Digital Commons @ University of South Florida. It has been accepted for inclusion in School of Geosciences Faculty and Staff Publications by an authorized administrator of Digital Commons @ University of South Florida. For more information, please contact digitalcommons@usf.edu. 


\title{
First Epoch Geodetic Measurements With the Global Positioning System Across the Northern Caribbean Plate Boundary Zone
}

\author{
T. H. DIXON, G. GONZALEZ, S. M. LICHTEN, AND E. KATSIGRIS
}

Jet Propulsion Laboratory, California Institute of Technology, Pasadena, California

\begin{abstract}
The first geodetic survey across the northem Caribbean plate boundary zone with the Global Positioning System (GPS) was conducted in June 1986. Baseline vectors defined by the six station regional GPS network ranged from 170 to $1260 \mathrm{~km}$ in length. Repeatability of independent daily baseline estimates was better than $8 \mathrm{~mm}$ plus 1.3 parts in $10^{8}$ of baseline length for horizontal components. The wet tropospheric path delay during the experiment was both high, sometimes exceeding 30 $\mathrm{cm}$ at zenith, and variable, sometimes exceeding $5 \mathrm{~cm}$ variation over several hours. Successful carrier phase cycle ambiguity resolution ("bias fixing") could not be achieved prior to construction of a regional troposphere model. Tropospheric calibration was achieved with water vapor radiometers at selected sites, and with stochastic troposphere models and estimation techniques at remaining sites. With optimum troposphere treatment and single-day orbital arcs, we resolved most biases on baselines up to about $550 \mathrm{~km}$ in length. With multiday orbital arcs we resolved most biases in the network regardless of baseline length. Our results suggest that constraints on plate boundary zone deformation in the Greater Antilles, and on the North America-Caribbean relative plate motion vector, can be obtained with a series of GPS experiments spanning less than 10 and 15 years, respectively.
\end{abstract}

\section{INTRODUCTION}

Relative motion of the Caribbean plate with respect to adjacent plates is poorly constrained. Global plate motion models [Jordan, 1975; Stein et al., 1988; Demets et al., 1990] and local models [Sykes et al., 1982] can place only indirect constraints on these vectors because transform fault azimuths, earthquake slip vectors, mid-ocean ridge spreading rates and other relative motion indicators are poorly defined, variable, sparse or nonexistent around the boundaries of this plate. Determination of the relative motion of the Caribbean plate with respect to North America is also made difficult by the fact that their common boundary is a complex, deforming zone. Within this plate boundary zone, the larger islands of the Greater Antilles (Hispaniola and Puerto Rico) may behave as rigid blocks ("microplates") or may themselves be internally deforming. Geodetic measurement of overall relative plate motion, relative motion among the larger crustal blocks within the boundary zone, and internal block deformation, can help to clarify the intricate kinematic relationships.

The accuracy requirements for such measurements are very stringent. Relative motion of the Caribbean plate with respect to North America, according to a recent model, is about $20 \mathrm{~mm} / \mathrm{yr}$ with an uncertainty of about $5 \mathrm{~mm} / \mathrm{yr}$ [Stein et al., 1988]. Geodetic measurement of this rate ideally should have an accuracy of $5 \mathrm{~mm} / \mathrm{yr}$ or better. Since a large fraction of the Caribbean plate boundary is either submarine or involves diffuse continental deformation zones [Burke et al., 1980, 1984], appropriate measurement sites that lie unequivocally on different plates can be separated by $300 \mathrm{~km}$ or more (Figure 1), making geodetic measurements challeng-

Copyright 1991 by the American Geophysical Union

Paper number 90JB02003.

0148-0227/9l/90JB-02003\$05.00 ing. Resolution of motion between possible microplates, or among individual fault blocks (e.g., in Hispaniola) is also important, and while possible with shorter baselines $(<300$ $\mathrm{km}$ in length), also requires rate accuracies of a few millimeters per year or better due to the low rates of motion involved. These requirements suggest the need for highaccuracy geodetic measurements over a wide range of baseline lengths.

Position accuracies of a few millmeters plus 1-2 parts in $10^{8}$ of baseline length have been suggested in the southwestern United States with Global Positioning System (GPS) measurements, based on comparisons to very long baseline interferometry (VLBI) data [Blewitt, 1989; Dong and Bock, 1989; Dixon et al., 1990]. However, it is not clear that this level of performance is easily extended to the Caribbean region, due to the possibly enhanced influence of two error sources for GPS geodesy: uncertainties in the orbits of the GPS satellites, and uncertainties in the signal propagation delay associated with passage through a variable, humid troposphere.

In June 1986 the first geodetic measurements spanning the northern Caribbean plate boundary zone were obtained with GPS. We present results from that experiment, and describe strategies for dealing with orbit- and troposphere-related errors. We also briefly review some geologic problems in the region to which GPS measurements may be relevant, focusing on the implied accuracy requirements.

\section{THE JUNE 1986 CARIBBEAN GPS EXPERIMENT}

The characteristics of the GPS system and its application to high-precision geodesy are reviewed in many recent publications [e.g., Remondi, 1985; Beutler et al., 1987; Lichten and Border, 1987; Tralli et al., 1988; Dong and Bock, 1989; Blewitt, 1989]. We review here only those aspects critical to this study. Briefly, dual-frequency carrier phase delay data from GPS satellites, with or without group delay data (often termed pseudorange) from the $P$ code and/or $C / A$ code, are recorded by ground receivers and analyzed for high-precision position information. Continuously tracked 


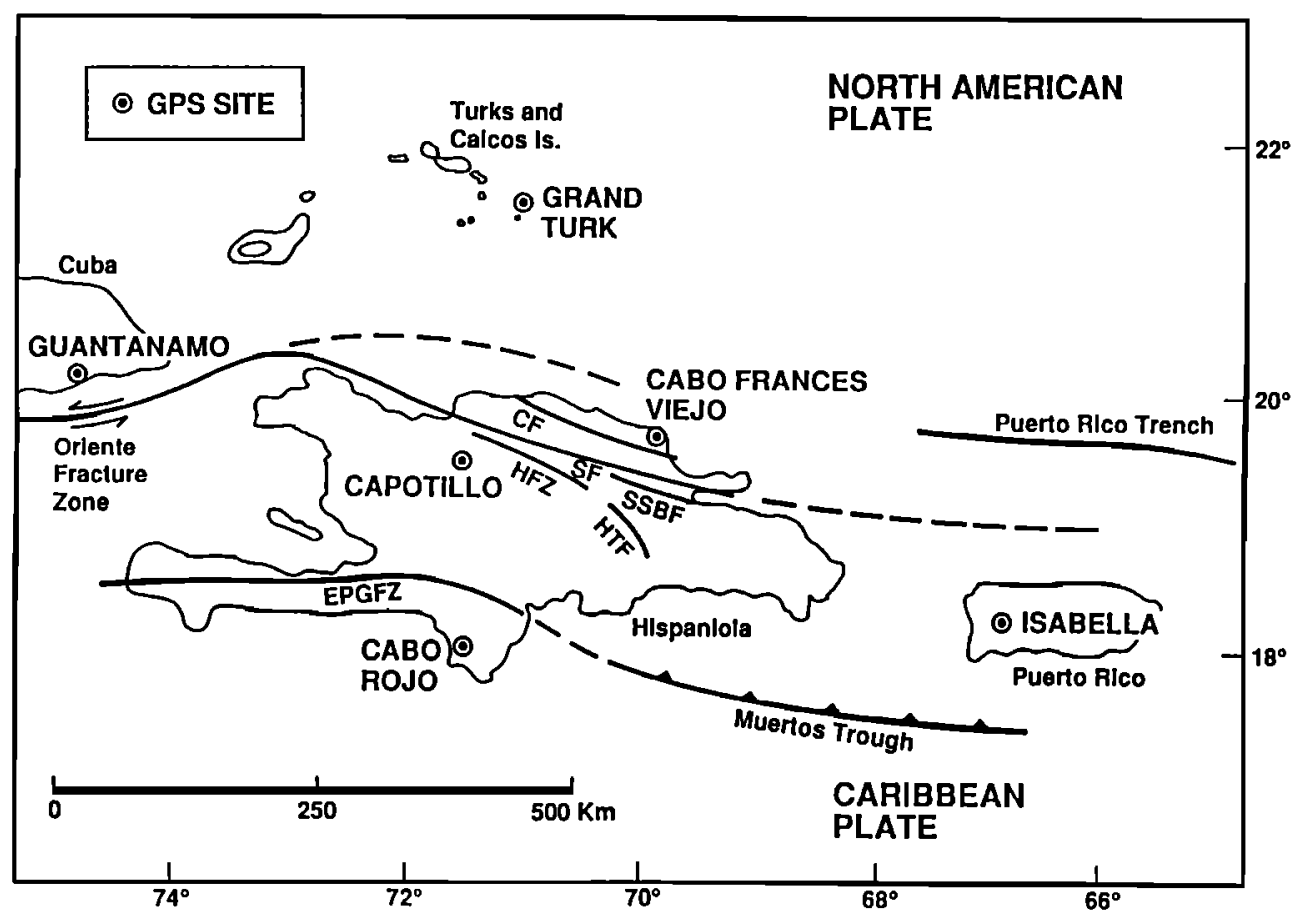

Fig. 1. Stations occupied for the June 1986 northem Caribbean GPS experiment. Some of the major faults in the region are shown, from Bowin [1975], Mann et al. [1984)] and Byrne et al. [1985)]. CF=Camu Fault; SF=Septentrional Fault; SSBF=South Samana Bay Fault; HFZ=Hispaniola Fault Zone; HTF=Hatillo Thrust Fault; EPGFZ=Enriquillo-Plantain Garden Fault Zone.

carrier phase data provide a precise measure of range change between the satellite and ground receiver, but the absolute range is ambiguous by an integer number of carrier wavelengths. In principle, $P$ code pseudorange data can provide the absolute satellite-receiver range biased only by satellite and receiver clock offsets but may not be available from some receiver types or may be noisy or contaminated by multipath effects. Other approaches are generally required to resolve the carrier phase cycle ambiguities. In this experiment, pseudorange data were available from the T14100 receivers in the network but not from the SERIES-X receivers (Table 1).

A necessary condition for obtaining high-precision geodetic data with GPS is precise knowledge of satellite orbits during the period of ground observations. Simultaneous tracking of the satellites from sites whose positions are well known from some other technique, such as VLBI, can provide the requisite information. Systematic errors in the locations of these "fiducial" sites, as well as limitations in their number and viewing geometry, lead to systematic errors in the orbit and baseline estimates of interest [Freymueller and Golombek, 1988]. These errors tend to scale with baseline length and can become the major error source on longer $(>300 \mathrm{~km})$ baselines [Dixon et al., 1985]. One limitation for GPS geodesy in the Caribbean region is that no fiducial sites exist at present within the region, and only 1 site (Richmond, Florida) is close. Thus it needs to be demonstrated that existing U.S. fiducial sites provide adequate constraints for high-precision GPS baseline estimation in the Caribbean region, particularly for longer baselines sensitive to orbit uncertainties.

The June 1986 Caribbean GPS experiment spanned 8 days from June 3 - 10. Eight sites in the continental United States were occupied (Table 1), along with six sites in the northern
Caribbean (Figure 1). Seven of the continental U.S. sites have had a history of VLBI observations and thus can act as fiducial sites or can define baselines for GPS accuracy tests through comparison of results from the two techniques. All the continental U.S. sites as well as Grand Turk and Guan-

TABLE 1. Sites and Equipment for the June 1986 Northem Caribbean GPS Experiment

\begin{tabular}{|c|c|c|}
\hline Location & Receiver & WVR \\
\hline $\begin{array}{l}\text { Ft. Davis, Texas" } \\
\text { Hat Creek, Califomia* } \\
\text { Haystack, Massachusetts* } \\
\text { Mammoth Lakes, Califomia } \\
\text { Mojave, Califomia* } \\
\text { Monument Peak, California* }\end{array}$ & $\begin{array}{l}\mathrm{TI} \\
\mathrm{TI} \\
\mathrm{TI} \\
\mathrm{TI} \\
\mathbf{S X} \\
\mathrm{TI}\end{array}$ & $\begin{array}{r}-- \\
\mathrm{R} 08 \\
- \\
\mathrm{R} 07 \\
-\end{array}$ \\
\hline $\begin{array}{l}\text { Ovro,Califomia* } \\
\text { Richmond, Florida* } \\
\text { Cabo Frances Viejo, } \\
\text { Dominican Republic }\end{array}$ & $\begin{array}{l}\mathbf{S X} \\
\mathbf{T I} \\
\mathbf{T I}\end{array}$ & $\begin{array}{r}\mathrm{R} 02 \ddagger \\
\mathrm{R} 05\end{array}$ \\
\hline $\begin{array}{l}\text { Cabo Rojo, } \\
\text { Dominican Republic }\end{array}$ & TI & SCAM 1 \\
\hline $\begin{array}{l}\text { Capotillo, } \\
\text { Dominican Republic }\end{array}$ & $\mathrm{TI}$ & - \\
\hline $\begin{array}{l}\text { Grand Turk, } \\
\text { Turks and Caicos Islands }\end{array}$ & $\mathrm{TI}$ & J01 \\
\hline $\begin{array}{l}\text { Guantanamo Bay, } \\
\text { Cuba }\end{array}$ & $\mathrm{TI}$ & R06 \\
\hline $\begin{array}{l}\text { Isabela, } \\
\text { Puerto Rico }\end{array}$ & $\Pi$ & R04 \\
\hline
\end{tabular}

*VLBI location data are available for these stations.

$\dagger_{T I}=\mathrm{TI}-4100 \mathrm{TM}$ receiver (Texas Instruments) and $\mathrm{SX}=$ Series $\mathrm{X}$ receiver.

\$High-quality WVR data were not obtained from these stations. 
tanamo are on the North American plate; the remaining four sites are on the Caribbean plate. The southernmost site, Cabo Rojo, was chosen because its location is south of most (but probably not all) of the plate boundary zone deformation in Hispaniola (Figure 1). The equipment used at each site is listed in Table 1.

A second necessary condition for high-precision geodesy with GPS is adequate characterization of wet tropospheric path delays. Three of the Caribbean sites, plus Richmond, Florida, had water vapor radiometers (WVRs) for calibration of the wet zenith delay. However, the quality of these varied. Only one site (Grand Turk) had a newer, three-channel model (J-01) suited for field operation; the remaining sites were covered with older, less robust two-channel units. Power interruptions and other problems occasionally limited GPS or WVR data acquired at a given site. The amount of GPS data recovered for each day of observation at the various sites is listed in Table 2. WVR data were available for most days at sites so equipped (Table 1). However, an inoperative elevation drive on the WVR at Cabo Rojo prevented this instrument from acquiring the "tipping curve" data required for selfcalibration. The instrument was operated in a vertical-only mode, with the expectation that these data would have lower accuracy, but might nevertheless provide some information on temporal fluctuations. Another goal of this study is to evaluate whether the tropospheric calibration afforded by our limited suite of WVRs is adequate for the entire Caribbean network.

If the carrier phase cycle ambiguity is not fixed by some technique but is estimated along with other geodetic parameters, precision of the horizontal baseline components is degraded by factors of 2 or more [Dong and Bock, 1989; Blewitt, 1989]. Most techniques available to resolve the ambiguities benefit from the existence of shorter $(<100-200$ $\mathrm{km}$ ) baselines in the network, where atmospheric (ionospheric plus tropospheric) calibration errors generally tend to be small. Unfortunately, wet tropospheric effects were significant even for the shortest $(168,184 \mathrm{~km})$ baselines in the Caribbean network. Wet path delays in the Caribbean were both high and variable during the experiment, sometimes exceeding $30 \mathrm{~cm}$ at zenith, and $5 \mathrm{~cm}$ variation over several hours. The high level of temporal fluctuations suggests the likelihood of large horizontal gradients in the wet tropospheric path delay [Treuhaft and Lanyi, 1987], a possibility supported by the observation that the variations were not correlated at adjacent sites in any obvious way. The associated path delay errors will therefore not tend to cancel on the shorter baselines as they might under more benign atmospheric conditions. If uncorrected, these errors inhibit resolution of the carrier phase cycle ambiguities. Thus a third goal of our study is to evaluate the extent to which data from the relatively sparse Caribbean network occupied in 1986, coupled with our tropospheric modeling and other analytical strategies, allow resolution of these ambiguities.

\section{DATA ANALYSIS}

All analyses were performed with the GIPSY (GPS Inferred Positioning System) data processing software. Of primary interest here are the modules GPSOMC (GPS Observed Minus Calculated), OAFILTER and AMBIGON. GPSOMC [Sovers and Border, 1988] calculates an accuiate model of the GPS observables based on nominal values of spacecraft and station positions and Earth orientation, and outputs prefit residuals and measurement partial derivatives. OAFILTER [Lichten, 1990a] is a least squares parameter estimation module and includes an upper triangular-diagonal (UD) factorized batch sequential Kalman filter [Bierman, 1977] with the capability to model and estimate process (colored) noise parameters. OAFILTER allows simultaneous estimation of satellite orbit parameters, satellite and ground station clocks, ground station positions, satellite solar radiation pressure coefficients and zenith troposphere parameters. The zenith tropospheric path delay or its residual after calibration can be modeled as a constant term or stochastically. AMBIGON [Blewitt, 1989] resolves the integer cycle carrier phase ambiguities and adjusts parameter estimates to improved values, exploiting the fact that the group delay of the $P$ code modulation is the same magnitude (though opposite sign) as the phase delay, provided the correct number of cycles has been assigned to the phase measurement.

Initial attempts to resolve the cycle ambiguities after simple tropospheric calibration were unsuccessful. We therefore concentrated first on identifying an optimum calibration approach for the wet tropospheric path delay [Tralli et al., 1988; Tralli and Lichten, 1990]. The atmosphere (mainly the troposphere) delays the GPS signal by an amount $p$ which can be expressed as

$$
p=\rho_{d}^{\circ} M_{d}(\theta)+p_{w}^{\circ} M_{w}(\theta)
$$

where $\rho^{\circ}{ }_{d, w}$ are the dry and wet zenith tropospheric delays, respectively, and $M(\theta)$ is a mapping function relating zenith path delays to delays at other elevations. The mapping functions are assumed to be azimuthally symmetric. We used the mapping function developed by Lanyi [1984], which accounts for ray bending and Earth curvature. The dry zenith delay is determined by measurement of surface pressure under the assumption of hydrostatic equilibrium. The wet zenith delay can be determined either by a WVR [e.g., Janssen, 1985] or by measurement of surface temperature and relative humidity, coupled with a simple atmospheric model [Chao, 1974]. For this experiment, surface meteorological (SM) measurements were taken at all sites, and water vapor radiometer measurements were taken at some sites (Table 1). WVR data were reduced from brightness temperature measurements to zenith wet path delay using the algorithm of Robinson [1988]. A subset of the data was also reduced using Gary et al.'s [1985] algorithm, and yielded similar results, generally within about $1 \mathrm{~cm}$ of the zenith wet path delay [Tralli and Lichten, 1990]. For both SM and WVR calibration, residual corrections to $\rho^{\circ}{ }_{w}$ were estimated along with geodetic parameters except as noted below.

The wet delay can also be corrected without prior calibration, by estimating it along with the geodetic parameters, relying solely on the geometric strength of the GPS data and the assumed elevation angle dependance of the atmospheric delay. The wet delay can be estimated as a constant, or as a time-varying, stochastic parameter; residual errors after SM or WVR calibration can be similarly modeled [Lichten and Border, 1987; Tralli et al., 1988; Tralli and Lichten, 1990]. A complete discussion of stochastic modeling of process noise is presented by Bierman [1977]. Because of its importance in the subsequent discussion, we summarize the major points below. Briefly, the temporal variation of the wet path delay, $\rho_{w}(t)$, or its residual after calibration can be modeled as a first-order Gauss-Markov process, defined by the stochastic differential equation:

$$
\frac{d \rho_{w}(t)}{d t}=\frac{-1}{\tau} \rho_{w}(t)+\omega(t)
$$


where $\tau$ is the correlation time of the stochastic process and $\omega(t)$ is a zero mean white process noise variable whose variance, $q$, is described by

$$
\left\langle\omega(t) \omega(t)^{\prime}\right\rangle=q_{\operatorname{con}} \delta\left(t-t^{\prime}\right)
$$

where angle brackets denote the expectation value operator, $\delta$ is the Dirac delta function, and the subscript "con" denotes a continuous process. Since $\rho(t)$ has a zero mean,

$$
\left.<\rho^{2}(t)\right\rangle=\sigma^{2}(t)
$$

Then,

$$
\frac{d \sigma_{\rho}^{2}(t)}{d t}=-\frac{2}{\tau} \sigma_{\rho}^{2}(t)+q_{\text {con }}
$$

For the steady state:

$$
\frac{d \sigma_{\rho}^{2}(t)}{d t}=0
$$

which implies

$$
q_{\operatorname{con}}=\frac{2}{\tau} \sigma_{s}^{2}
$$

where $\sigma_{s s}$, the steady state sigma, is the noise level of $p(t)$ reached after $t \gg \tau$. As $\tau$ approaches infinity, a GaussMarkov process approaches a random walk, and $\sigma_{s s}$ becomes unbounded. It is nevertheless possible to characterize the random walk process in terms of the rate of change of $q$. It is convenient to consider the case for discrete time "batches," because the tropospheric calibrations are taken as discrete samples of a continuous process. The GPS observables are also discrete, being compressed to 30-s samples in the receiver and 6-min averages in our initial analysis, and the measurements are processed in discrete time batches via covariance matrix updates [see Lichten, 1990a]. In the discrete time form,

$$
\rho_{j+1}=m_{j} \rho_{j}+W_{j}
$$

where $j$ is the batch interval, $\rho_{j}=\rho\left(t_{j}\right)$, and $m$ and $W$ are the process noise weighting factor and the discrete form of the zero mean process noise, respectively, defined by

$$
\begin{gathered}
\mathrm{m}_{j}=\exp \left(-\left(t_{j+1}-t_{j}\right) / \tau\right) \\
\mathrm{w}_{j}=\int_{j}^{t_{j+1}} \exp \left(-\left(t_{j+1}-\zeta\right) / \tau\right) \omega(\zeta) d \zeta
\end{gathered}
$$

Finally, it can be shown [Bierman, 1977] that

$$
\begin{aligned}
\left\langle W_{j}^{2}\right\rangle & =\Delta q_{\mathrm{dis}} \\
& =\frac{\tau}{2}\left(1-m_{j}^{2}\right) q_{\mathrm{con}} \\
& =\left(1-m_{j}^{2}\right) \sigma_{s s}^{2}
\end{aligned}
$$

where $\Delta q_{\text {dis }}$ is the discrete process noise variance added to the system per batch interval. The rate of change of the dis- crete process noise variance being added to the system in the next batch is just

$$
\dot{q}_{\mathrm{dis}}=\frac{\Delta q_{\mathrm{dis}}}{\Delta t}
$$

where $\Delta t$ is the batch interval $(6 \mathrm{~min})$. We define the random walk parameter, $\alpha$, as a convenient way of characterizing our stochastic troposphere models:

$$
\alpha=\sqrt{\frac{\Delta q_{\text {dis }}}{\Delta t}}
$$

The random walk parameter is a measure of the magnitude of typical variation of the zenith path delay or its residual after calibration in a given time. The Allan (two sample) variance, $\sigma_{A}{ }^{2}$ [Allan, 1966], can also characterize troposphere fluctuations [Thompson et al., 1986; Treuhaft and Lanyi, 1987], and, for a random walk, is related to $q_{\mathrm{dis}}$ :

$$
\sigma_{A}^{2}(\Delta t)=\frac{\dot{q} \text { dis }}{\Delta t}
$$

In this study, random walk models of the zenith wet path delay or its residual after SM or WVR calibration are constructed, described simply by different values of $\alpha$. This yields results very similar to those obtained with the GaussMarkov process noise model [Tralli and Lichten, 1990]. More importantly, as we will show, this approach provides precise "calibration" of wet tropospheric path delay effects, even at sites where WVR data are not available or are of poor quality. Where WVR data are available, we can compare the empirically determined values of $\alpha$ obtained in our stochastic estimation approach to actual values based on the WVR measurements; if the values are similar, this suggests that our tropospheric model is physically plausible. The WVR-based values of $\alpha$ were determined following the approach of Tralli et al. [1988] and Tralli and Lichten [1990].

Table 3 lists a typical parameter estimation strategy. Data from each day were first processed separately and different approaches for troposphere calibration were tested. Site days with less than 1006 -min "compressed" data points (Table 2) were omitted from this preliminary analysis, as results indicated a high degree of scatter and large postfit residuals when these data were included, regardless of tropospheric treatment. Cycle ambiguities were resolved to the extent possible. To assess performance of various tropospheric calibration schemes, we considered day-to-day scatter (defined below) over the 4 to 8 available days, (e.g., Figures 2 and 3), mean baseline solutions, postfit residuals, comparison of estimates of wet tropospheric path delay from SM or WVR calibration with estimates based solely on GPS data, and the percentage of successfully resolved cycle ambiguities. The day-to-day scatter, or repeatability, $R$, of a vector baseline component (east, north or vertical) is defined as

$$
R=\left(\frac{\frac{n}{n-1} \sum_{i=1}^{n} \frac{\left(C_{i}-<C>\right)^{2}}{\sigma_{i}^{2}}}{\sum_{i=1}^{n} \frac{1}{2}}\right)^{\frac{1}{2}}
$$




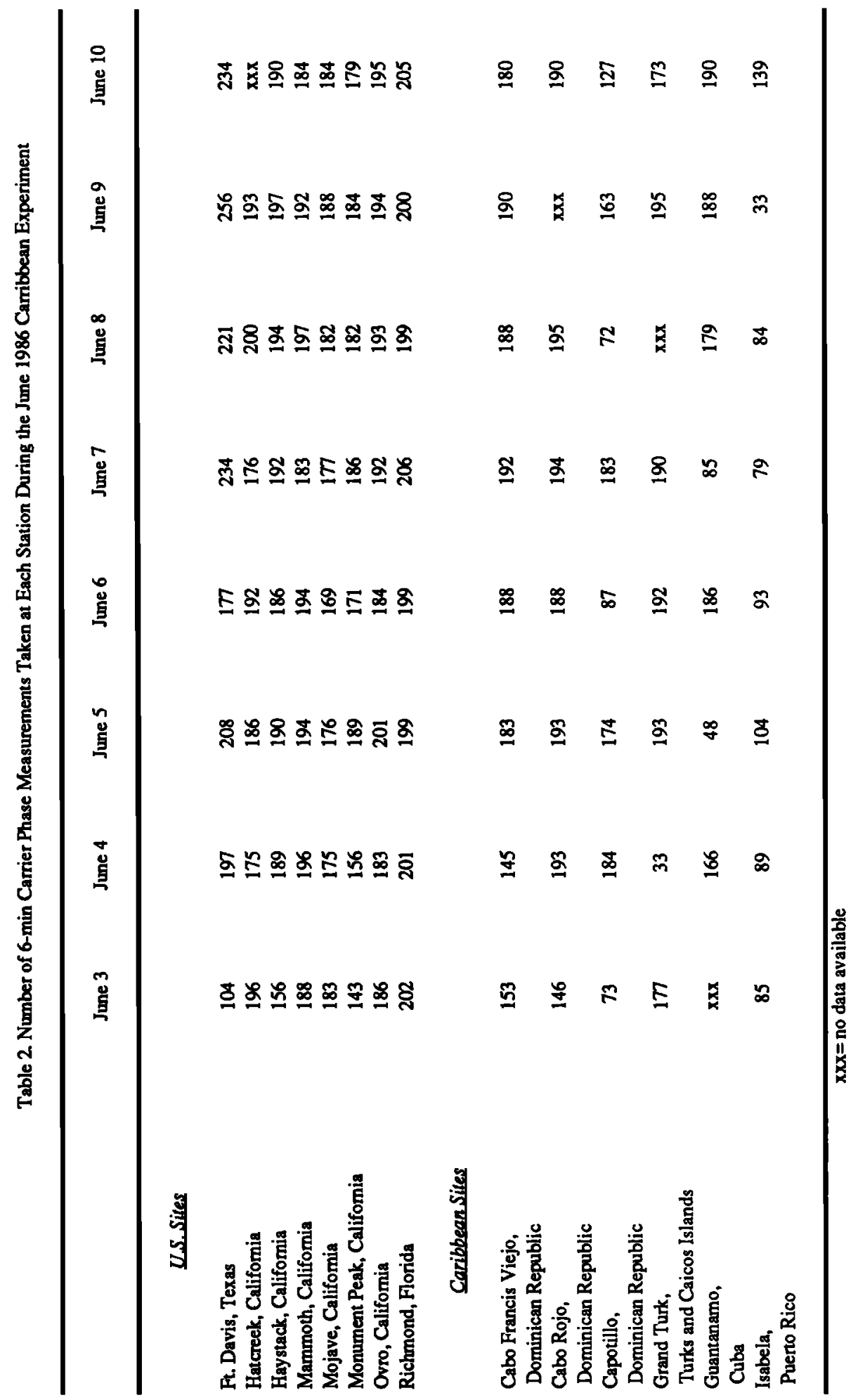


TABLE 3. Estimated Parameters, A Priori Sigmas and Data Weights Used for Analysis of the June 1986 Caribbean GPS Data.

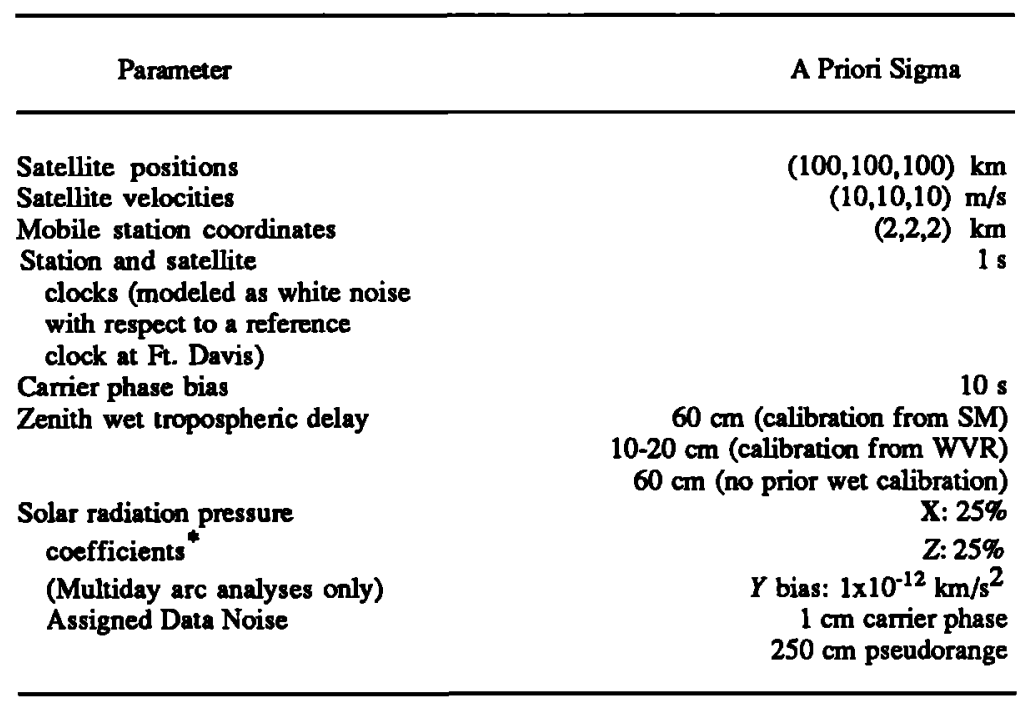

"Estimated as constants; a priori sigmas listed as percent difference from nominal value for $\mathrm{X}$ and $\mathrm{Z}$ components in local spacecraft reference frame.

where $n$ is the number of days, $C$ is the estimate of the component on day $i,\langle C\rangle$ is the weighted average of the component estimate over all days, and $\sigma_{i}$ is the formal error (unless noted, all uncertainties in this paper are at the $1 \sigma$ level). For stochastic models of either the entire wet delay or its residual after calibration, several trial runs were made to determine values of $\alpha$ that minimized day-to-day scatter and/or (for SM calibration and no calibration cases) gave troposphere solutions with temporal variation most similar to the WVR measurements. For the SM calibration and no calibration cases, actual baseline solutions obtained with different stochastic models were also compared to the WVR-calibrated baseline estimates where these were available.

With optimized fiducial and tropospheric calibration strategies, we were able to achieve reasonable levels of repeatability for baselines less than about $500 \mathrm{~km}$ in length. Baselines longer than this had a higher degree of scatter, suggesting that orbit uncertainties were contributing significant errors to the baseline estimates. We therefore employed a multiday arc approach in an attempt to reduce these errors. The advantages of multiday arcs have been described by Lichten and Border [1987] and Lichten and Bertiger [1989] and derive mainly from the visibility of the satellites from the ground during multiple orbit revolutions. With observations over more than one revolution, orbital periods and the positions of the orbital nodes are better determined. The down-track satellite position and velocity components especially benefit from the multiday arc treatment, which is sometimes manifested by a corresponding improvement in the east component baseline accuracy. Another advantage is simply related to the $1 / \sqrt{ } n$ improvement in precision of the orbital component estimate, where $n$ is the number of measurements.

\section{RESULTS}

\section{Fiducial Strategy}

We chose four sites (Hat Creek, California, Ft. Davis, Texas, Richmond, Florida, and Haystack, Massachusetts) of the seven possible fiducial sites to provide the necessary satellite ephemeris information for most of our analyses. Our choice of fiducial sites was based on common receiver type and data strength (Tables 1 and 2) coupled with the desire to get the largest possible east-west and north-south extent in the tracking network. Occasionally, weak data or complete data loss at one or more sites (Table 2) required us to substitute a fiducial site or use only three fiducial sites in the analyses. A three-fiducial site network consisting of the above stations minus Ft. Davis resulted in slightly greater formal errors and scatter in the day-to-day baseline estimates for the single day arc runs but otherwise did not affect results significantly, probably because the geographic extent of the network was similar. Omission of Hat Creek, Richmond or Haystack from the four-station network affected results to a greater extent, particularly for baselines longer than 500 $\mathrm{km}$. For the multiday arc runs, which are more sensitive to fiducial station location, best results were achieved with the network described above, but with the position of Fort Davis estimated with loose a priori constraints, perhaps reflecting some uncertainty in the site tie or monument location at this station. Based on this experience we suggest that a four- to five-fiducial station network with the same or similar northsouth and east-west extent as our "core" fiducial network provides adequate coverage for Caribbean baseline estimates and provides redundancy against data outages or site tie problems at one or two sites.

\section{Tropospheric Calibration}

To simplify analysis and comparison of various wet delay treatments, initial solutions were derived without bias fixing, using single-day fits to the orbits. Troposphere models at Ft. Davis, Texas, Haystack, Massachusetts, and the California sites were held fixed or were varied only within a limited range in this preliminary analysis, while models at Richmond, Florida, and the Caribbean sites were varied over a wider range due to greater atmospheric variability at these sites. Three stations in the latter group (Richmond, Cabo Rojo and Grand Turk) were the initial focus of the study 
because of their humid atmospheres, WVR data availability, and data strength (Tables 1 and 2). We begin our discussion with comparisons of baseline repeatability from these preliminary analyses for various tropospheric calibration strategies on some shorter $(<300 \mathrm{~km})$ baselines, where tropospheric calibration errors likely dominate other error sources such as orbits.

Baseline estimates incorporating corrections to SM calibrations for the wet delay had lower day-to-day scatter than those using SM calibrations alone (Figure 2). Estimation of residual zenith wet delay parameters after WVR calibration also improved precision relative to the case where no correction was applied (Figure 3). In general, the magnitude of the residual corrections was larger for SM calibration than for WVR calibration, indicating that on average the WVR measurements gave a better estimate of the total wet zenith delay. However, there were several cases of large $(>10 \mathrm{~cm})$ apparent errors in the WVR measurements, likely due to local rain or gross miscalibration of the instrument (see below), both of which affect the accuracy of the WVR measurement. For SM calibration, estimating a time-varying (stochastic) wet delay residual to the calibration was superior to estimating a constant residual (Figure 2). For WVR calibration, constant and stochastic residual error models gave similar results, with differences exceeding $1 \mathrm{~cm}$ repeatability in only a few of the vertical component estimates (e.g., Figure 3). In every case, however, solving for a residual correction (either constant or stochastic term) improved the quality of the vertical estimate with WVR calibration, and generally improved the horizontal components, though less consistently. The optimum stochastic residual error model for SM calibration also allowed a higher level of temporal fluctuations (i.e., larger value of $\alpha$ ) relative to the best WVR stochastic residual error model. These observations suggest that while the WVRs may have a bias, this bias does not have significant time

\section{SM CALIBRATION: RESIDLIAL ERROR TREATMENT}

\section{Cycle Ambiguities Estimated}
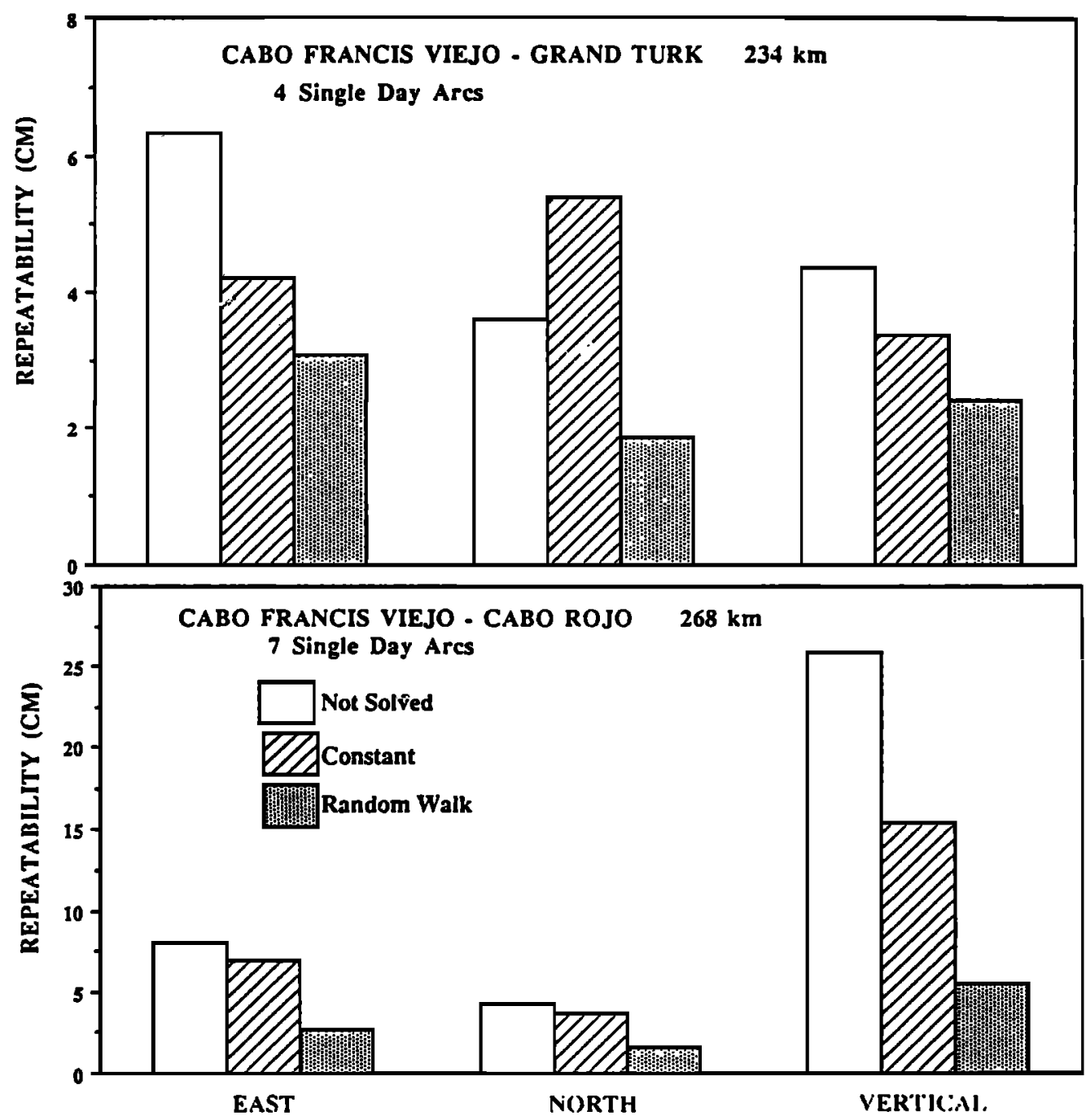

Fig. 2. Comparison of initial baseline repeatability ( $\mathrm{ms}$ scatter about the weighted mean of several independent days of data; equation [15]) without bias fixing for various treatments of residual wet tropospheric delays after surface meteorology (SM) calibration on two representative baselines. Residual error treatments are no correction (SM calibration is assumed perfect); constant correction (a single error value is estimated over the approximately 6-hour observation period); and a random walk correction (see text) using a value of $\alpha=1.2 \mathrm{~cm} / \mathrm{hhr}$. 
WVR CALIBRATION: RESIDUAL ERROR TREATMENT Cycle Ambiguities Estimated
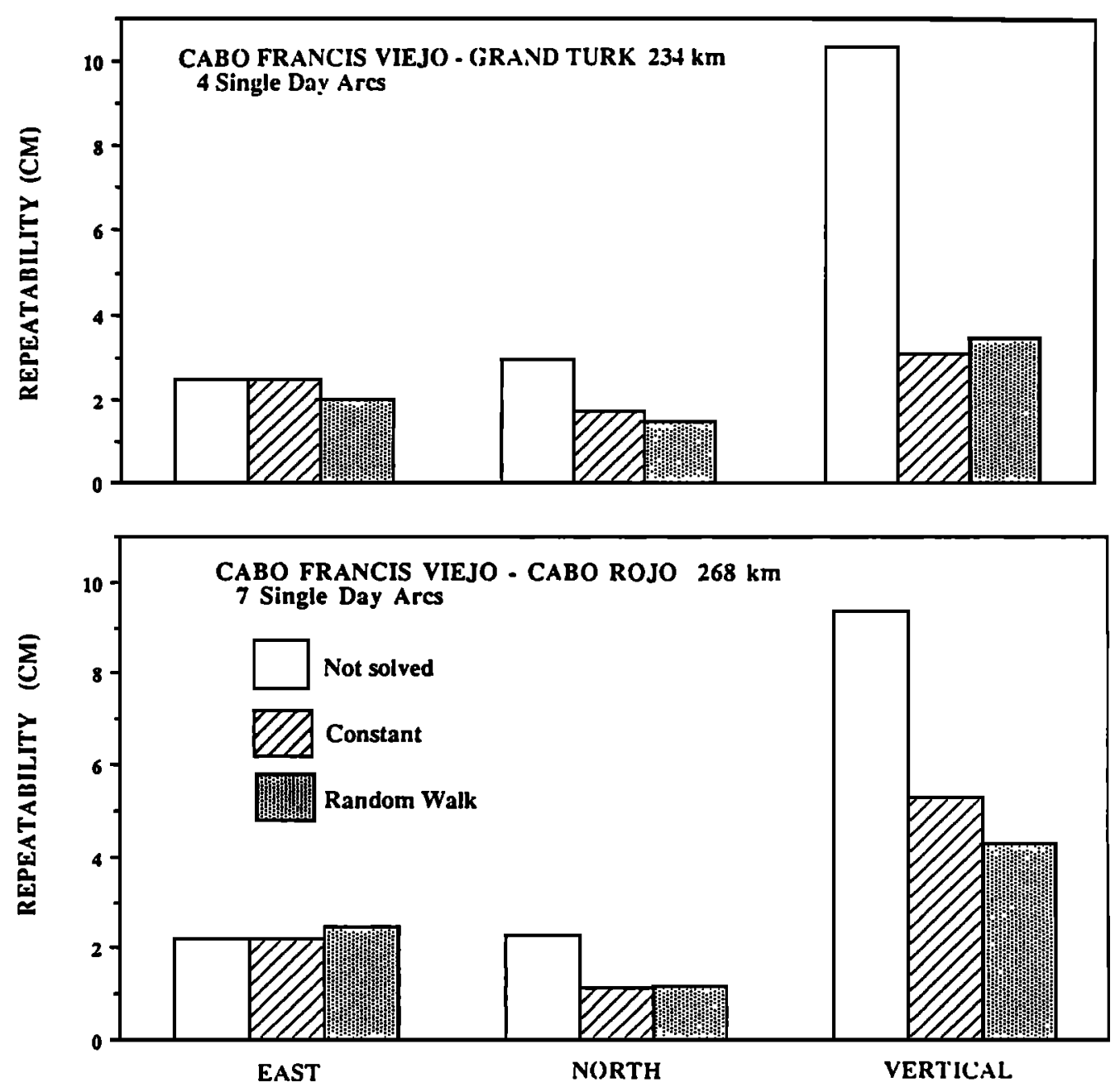

Fig. 3. Similar to Figure 2, for various treatments of residual delay after water vapor radiometer (WVR) calibration. Residual error treatments are no correction (WVR calibration assumed perfect); constant correction; and a random walk correction with $\alpha=0.5 \mathrm{~cm} / \mathrm{Vhr}$. Note that WVR is deployed at one end of baseline only (Table 1).

variation and thus is adequately corrected by estimating a constant residual, or with a stochastic model allowing only small time variation. The WVR measurements thus appear to give a good estimate of the time-varying component of the wet tropospheric path delay. In contrast, the SM calibration errors appear to fluctuate significantly in time.

The accuracy of WVR calibration must be about $1 \mathrm{~cm}$ or better in zenith wet path delay in order to significantly improve VLBI baseline estimates [Herring, 1986; Elgered et al., 1990]. Similar requirements likely apply to GPS [Dixon and Kornreich Wolf, 1990]. The precision of the zenith wet path delay measurement with current generation WVRs is better than $1 \mathrm{~cm}$ [e.g., Janssen, 1985], but the actual accuracy achieved in a given field experiment is not well known, and may depend on site, season, weather, the specific instrument and operating conditions, and the algorithm used to convert antenna brightness temperature measurements to path delay. Errors in the mapping function used to relate zenith delays to delays at lower elevations may also limit accuracy [Davis et al., 1985]. Our preliminary analysis suggested that in general the WVR calibrations available for the Caribbean sites were not accurate at the 1$\mathrm{cm}$ level, based on the magnitude of the residual delay corrections noted above. The largest corrections (exceeding $10 \mathrm{~cm}$ ) occurred at Cabo Rojo, where the inoperative elevation drive disabled the standard "tipping curve" calibration. Some other large $(2-4 \mathrm{~cm})$ differences occur at a few sites on days when rainfall was reported. The presence of liquid water in the atmosphere can render the WVR estimate of water vapor invalid. Rain or condensation on the antenna housing can also contribute significant near-field radiation, increasing system noise. Together, these effects can lead to several centimeters or greater deviations in the estimate of the zenith wet path delay. Most of the Caribbean sites reported scattered rain showers on several days, and large cumulus buildups were common throughout the experiment. These observations suggest that there are uncertainties in the WVR zenith wet path delay estimates for this experiment exceeding $1 \mathrm{~cm}$. Our best baseline estimates therefore used WVR data at some sites only as a guide to temporal fluctuations at a given site (Table 4), suggesting initial trial stochastic troposphere models (see below), or used WVR data 
TABLE 4. Random Walk Parameter ( $\alpha, \mathrm{cm} / \mathrm{hrr}$ ) for the Zenith Wet Path Delay Based on WVR Measurements

\begin{tabular}{lcccccccc}
\hline & June 3 & June 4 & June 5 & June 6 & June 7 & June 8 & June 9 & June 10 \\
& & & & & & & & \\
Haystack & 2.04 & 0.60 & 2.10 & 0.90 & 3.30 & 1.26 & 1.98 & 0.84 \\
Mojave & 0.48 & 0.42 & $\mathbf{x x x}$ & 0.42 & 0.42 & 0.42 & 0.42 & 0.36 \\
Richmond & 1.14 & 1.38 & 0.84 & 0.48 & 0.66 & 1.26 & 0.48 & 1.38 \\
Cabo Rojo & 2.40 & 1.62 & 1.32 & 1.80 & 2.58 & 1.86 & 2.88 & 1.98 \\
Grand Turk & 1.68 & 2.34 & 0.90 & 0.72 & 0.84 & 1.20 & 0.60 & 0.78 \\
Isabela & 0.78 & 3.60 & 1.62 & 2.22 & 3.06 & 1.02 & 0.78 & 0.90 \\
\hline
\end{tabular}

with residual error models that allowed several centimeters of correction (Table 5).

With no prior calibration, the entire wet delay can be estimated along with the geodetic parameters of interest, based solely on the geometric strength of the GPS data. The zenith delay can be estimated as either a constant or time-varying stochastic parameter. The stochastic method was always superior. A series of trial runs were performed using this "no calibration" approach with various values of $\alpha$ to model the wet zenith path delay. Comparison of day-to-day repeatability on several representative baselines suggested optimum values of $\alpha$ approximately in the range $1.0 \mathrm{~cm} / \mathrm{Vhr}$ to 2.0 $\mathrm{cm} / \mathrm{hhr}$. Note that it is not adequate to place an arbitrarily loose constraint on this parameter to cover all possible sites and situations; the random walk model for the wet path delay must be constrained to approximately the "correct" value (within a factor of $\sim 2$ based on the limited number of trials performed for this study) to obtain optimum baseline estimates. Values of $\alpha$ that are too large weaken the GPS data strength for geodetic parameter estimation, while values that are too small may introduce systematic errors.

The values of $\alpha$ that gave the best repeatability for the Caribbean baselines (Table 5) were, within a factor of 2 , similar to the average values of the wet troposphere variability measured by the WVRs at the tropical sites (Table 4). The total range of measured daily values of $\alpha$ in the Caribbean region (including Richmond) was $0.5-3.6 \mathrm{~cm} / \sqrt{\mathrm{hr}}$. The range measured by the newer three-channel WVR at Grand Turk was $0.6-2.3 \mathrm{~cm} / \mathrm{Vhr}$, with a mean of $1.1 \mathrm{~cm} / \mathrm{Vhr}$. In general, the higher values correspond to days where rain or stormy weather are reported. We cannot determine whether these high values reflect actual greater variability during stormy weather, or inaccuracy of the WVR in the presence of significant liquid water in the atmosphere. The values listed in Table 5 are similar to the range of stochastic models used by Tralli and Lichten [1990] in the Gulf of California and Dixon and Kornreich Wolf [1990] in Central America. At least for these examples it appears that the humid troposphere can be characterized adequately with a fairly limited range of stochastic models. Of course, this might only reflect the coincidence of similar weather conditions, and more experiments will be required before the general applicability of such models can be determined.

Table 5 summarizes our final stochastic models. Best results were achieved using WVR calibration where available with residual delays estimated stochastically, and, at remaining sites, estimating the entire wet zenith delay with stochastic models allowing greater fluctuations. The level of atmospheric variability, coupled with the resolution of the data, did not permit distinct models to be constructed for each Caribbean site, but there were clear advantages to separate models for the Caribbean and continental U.S. sites.

\section{Cycle Ambiguity Resolution}

Once the troposphere treatment was optimized, it was feasible to attempt carrier phase cycle ambiguity resolution (bias fixing). Attempts to fix the biases on the Caribbean baselines prior to optimizing the troposphere treatment were largely unsuccessful. Bias fixing was more successful within the Caribbean network when the tropospheric calibration scheme described above was employed, with more than $90 \%$

TABLE 5. Final Stochastic Model Parameters for Zenith Wet Tropospheric Path Delay (Entries are $\alpha$ (equation (13), text) in $\mathrm{cm} / \sqrt{\mathrm{hr}}$.)

\begin{tabular}{|c|c|c|c|c|c|c|}
\hline & \multicolumn{2}{|c|}{ Califomia } & \multirow{2}{*}{$\begin{array}{c}\text { Ft. Davis, } \\
\text { Texas } \\
\text { No WVR }{ }^{\dagger}\end{array}$} & \multirow{2}{*}{$\begin{array}{l}\text { Cabo Rojo } \\
\text { Dominican } \\
\text { Republic } \\
\text { WVR* }\end{array}$} & \multicolumn{2}{|c|}{$\begin{array}{l}\text { Remaining Caribbean } \\
\text { Sites Plus } \\
\text { Richmond, Florida }\end{array}$} \\
\hline & $\overline{\mathrm{WVR}^{*}}$ & $\overline{\text { No WVR }}{ }^{\dagger}$ & & & $\overline{W V R^{*}}$ & No WVRt \\
\hline June $3.4^{\S}$ & 1.2 & 1.2 & 1.8 & 1.8 & 1.2 & 2.4 \\
\hline June 5-10 & 1.2 & 1.2 & 1.8 & 1.8 & 1.2 & 1.8 \\
\hline
\end{tabular}

"Residual delay estimated stochastically.

†Entire wet delay estimated stochastically. Note lower level of fluctuations for California sites.

†This residual delay model allows higher temporal fluctuations to account for lack of tip curve calibration.

\$The stochastic model for Caribbean sites without WVRs on these 2 days allows higher temporal fluctuations to account for stormy weather through most of the region. 
of the biases resolved for baselines shorter than about $\mathbf{5 5 0}$ $\mathrm{km}$. For longer baselines, we were unable to resolve most of biases with single-day orbital arcs, which motivated the multiday arc strategy discussed in the next section. Figure 4 shows baseline repeatability before and after bias fixing for single-day arcs for all baselines among sites in the Caribbean network including Richmond, Florida, spanning up to about $1260 \mathrm{~km}$ in length. Repeatability of horizontal components was improved by factors of 2 or more after bias fixing for most baselines shorter than $550 \mathrm{~km}$, and caused smaller or no improvements on the longer baselines where we were unable to resolve biases. Precision of the vertical estimate was not affected significantly by bias fixing the single-day orbital arc data. Similar results were obtained by Blewitt [1989] and Dong and Bock [1989] for GPS baseline estimates in southern California.

To illustrate the sensitivity of resolving biases in this data set to tropospheric calibration, we intentionally degraded the calibration by specifying nonoptimum random walk models. Figure 5 shows the results of a series of runs made where the wet troposphere was modeled stochastically, using a single average value of $\alpha$ at all Caribbean sites without WVRs; the values in Table 5 were used for the remainder of the network. Values of $\alpha$ either looser or tighter than the

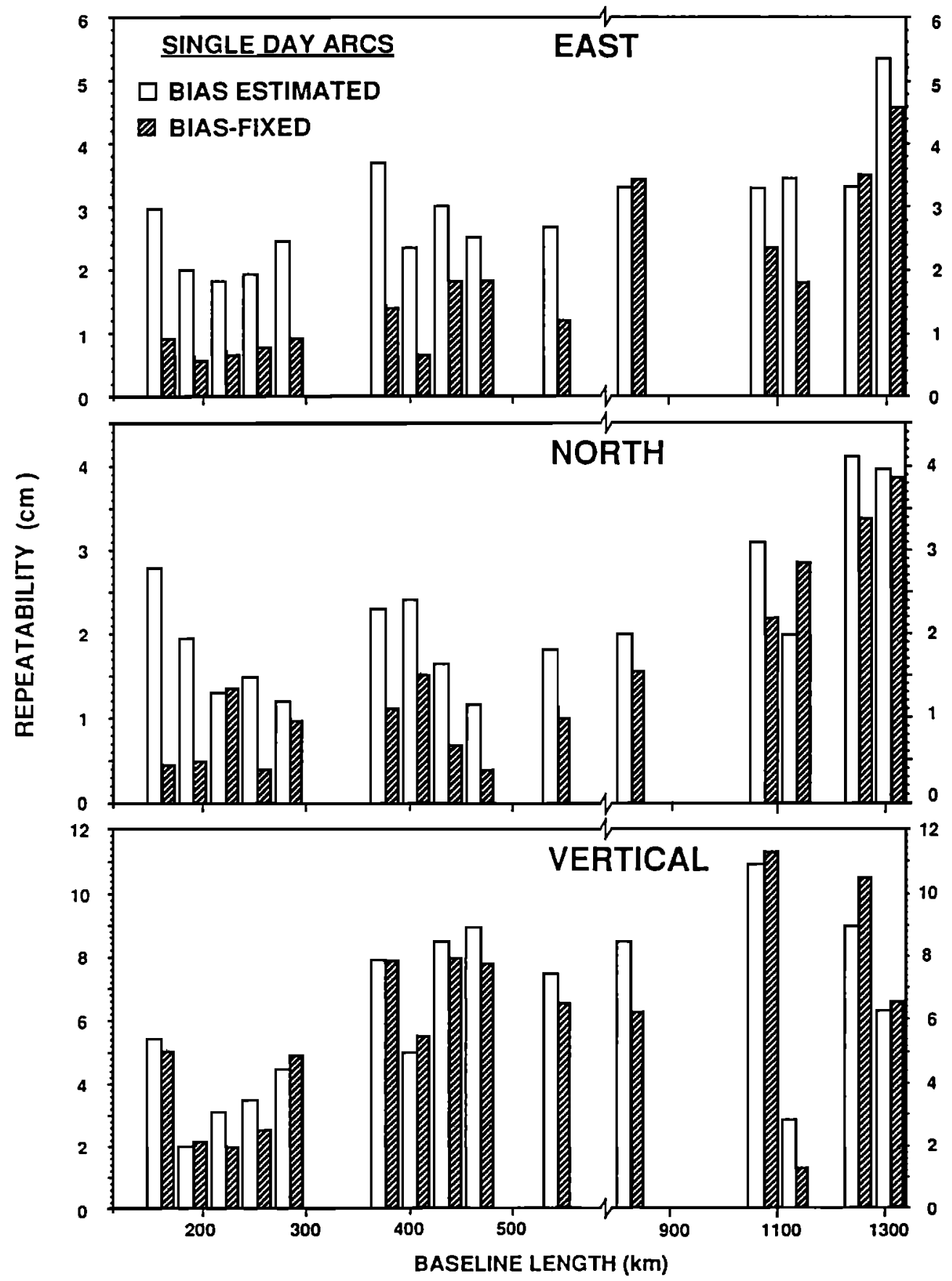

Fig. 4. Histograms of baseline repeatability (equation [15]) plotted approximately as a function of baseline length (some baselines displaced slightly for clarity) before and after resolution of carrier phase cycle ambiguities (bias fixing) for single-day orbital arcs and optimized wet troposphere treatment. Note improvement with bias fixing in horizontal (east, north) components for baselines shorter than $550 \mathrm{~km}$ and scale change at $550 \mathrm{~km}$.. 


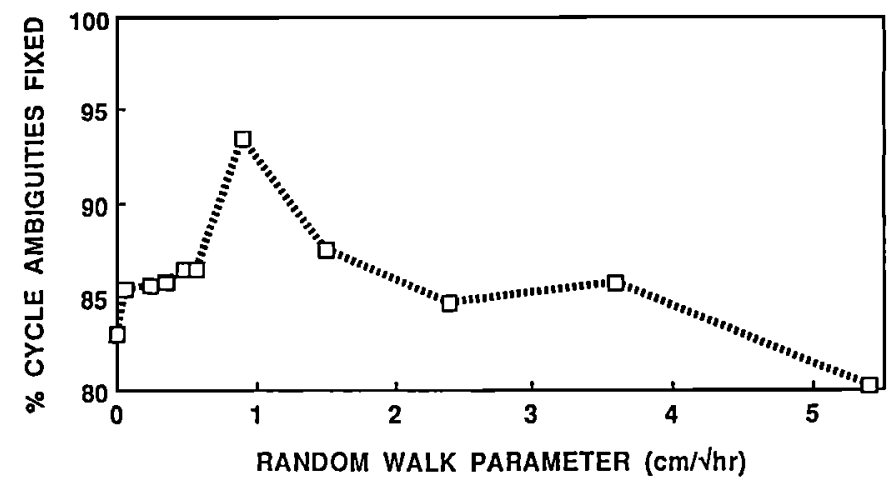

Fig. 5. Number of carrier phase cycle ambiguities (biases) resolved as a function of wet tropospheric path delay model. Tropospheric treatment is held fixed at the U.S. fiducial sites and at the Caribbean sites where WVR calibration is available. A single random walk model for the entire zenith wet tropospheric path delay is varied at the remaining Caribbean sites as shown. Random walk parameter ( $\alpha$ ) $=0$ indicates wet zenith path delay modeled as constant.

optimum average value affected the number of biases that could be resolved in the network. Note that this optimum value $(1.0 \mathrm{~cm} / \mathrm{hr})$ is close to the average value measured by the three-channel WVR at Grand Turk (1.1 cm/ $/ \mathrm{hr}$; Table 4).

The bias-fixed results allow a more rigorous evaluation of the relative merits of various tropospheric calibration schemes for this experiment. Each scheme must be implemented in a near-optimum manner in order to achieve biasfixed baseline estimates, and the overall improvement in precision with bias fixing means that we can better compare the relative merits of each approach. Figure 6 is similar to Figure 3, except now we plot repeatability of baseline estimates with biases fixed (to the extent possible) for various treatments of the residual delay after WVR calibration. The results of the residual error treatments shown in Figure 6 are generally similar to those in Figure 3, but as expected the repeatability in the horizontal components is improved in the bias-fixed case. The exception is the case where no correction is applied to the WVR calibration; the bias-fixed and bias-estimated results are similar. This occurs because in the so-called bias-fixed case, many of the biases could not actually be resolved. This indicates that systematic errors in the calibration, if uncorrected, may be serious enough to preclude bias-fixing.

Figure 7 compares the repeatability of bias-fixed, WVRcalibrated baseline estimates using an optimum residual error treatment (from Figure 6) with bias-fixed baseline estimates using our "best" stochastic model for the entire wet tropospheric path delay. The results of the two methods are very similar. The largest difference in repeatability is a $1.5-\mathrm{cm}$ difference in the vertical component estimates for the Cabo Francis Viejo-Grand Turk baseline, which, given the precision of the vertical component estimate, is not significant. These observations suggest that for this experiment, WVR calibration did not improve results relative to stochastic estimation of the entire wet delay. The same conclusion was reached for GPS experiments in the Gulf of California [Tralli et al., 1988] and Central America [Dixon and Kornreich Wolf, 1990]. However, these are not definitive tests of WVR utility, for several reasons. First, the quality and quantity of the WVR calibration available was far from ideal. Perhaps with high-quality WVRs deployed at all sites within a network, improvements in baseline estimates with WVR calibration would be more apparent. Second, the WVRs avail- able to us for this experiment, as with the experiments just cited, did not operate in a "line of site" mode, but rather gave zenith delay estimates only. In the presence of azimuthal asymmetries in the wet path delay, this difference could be important, and line of site calibration with WVRs would presumably be advantageous. The temporal variability in the wet zenith delay at many Caribbean sites leads us to suspect that such asymmetries were in fact present during the experiment. Third, there are statistical limitations in the type of comparisons we can employ with available data, which involve results with and without WVR calibration over several days. Consider the data described in Figure 7, where data availability for the Cabo Francis Viejo-Grand Turk baseline limits the comparison to just 4 days. The observation days can be considered independent trials $(n=4)$ with $n-1=3$ degrees of freedom. A simple $\chi^{2}$ test to determine the confidence limit for our determination of repeatability $(\sim \sigma)$ suggests that at the $95 \%$ confidence limit the repeatability of the vertical component estimate of this baseline with WVR calibration, nominally $2.5 \mathrm{~cm}$, could be as low as $1.4 \mathrm{~cm}$. For stochastic estimation of the entire delay, the repeatability, nominally $1.0 \mathrm{~cm}$, could be as high as $3.7 \mathrm{~cm}$. The two values are similar within uncertainties, and the apparent "failure" of WVR calibration relative to stochastic estimation for this baseline is not statistically significant. All we can say given our limited data is that there is no significant difference between WVR calibration and stochastic estimation techniques.

Finally, we note that the ability to resolve the carrier phase biases in the Caribbean network also depended on the number and geometry of stations in the network and the corresponding existence of several relatively short (168, $184 \mathrm{~km}$ ) baselines. Omission of one or more sites in the network significantly affected the ability to resolve the biases, depending on the resulting network geometry.

\section{Multiday Arcs: Reducing Orbit Errors}

Once troposphere treatment was optimized and carrier phase biases resolved to the extent possible, it was apparent that repeatability correlated strongly with baseline length (Figure 4), suggesting the influence of orbit-related errors. We therefore formed multiday orbital arcs of up to 3 days by specifying longer solution intervals in GPSOMC and FILTER in an attempt to improve the orbit estimates, resolve biases on longer baselines, and reduce baseline errors. The method is described fully by Lichten and Bertiger [1989]. A single set of estimates for the GPS epoch states, including constant corrections to three solar pressure coefficients for each spacecraft, was determined from all the data in the multiday pass. The zenith troposphere correction at each ground site or its residual after calibration was estimated stochastically as described above; however, from one day to the next, the troposphere parameters were reset so that they were determined as separate parameters. In addition, separate station solutions were obtained for each day, and these positions were compared as before to assess baseline repeatability.

The data were divided into three arcs: June 3-5, June 6-7, and June 8-10. The June 3-5 arc produced slightly weaker solutions because some of the Caribbean sites and Fort Davis produced incomplete data on the first day (Table 2), and Fort Davis (normally a fiducial site) had no site vector recorded on June 5; its position was estimated in the multiday arc analysis. The multiday arc solutions were bias-fixed as before. A major difference between the single-day and multiday arc 


\section{WVR CALIBRATION: RESIDUAL ERROR TREATMENT} Cycle Ambiguities Resolved

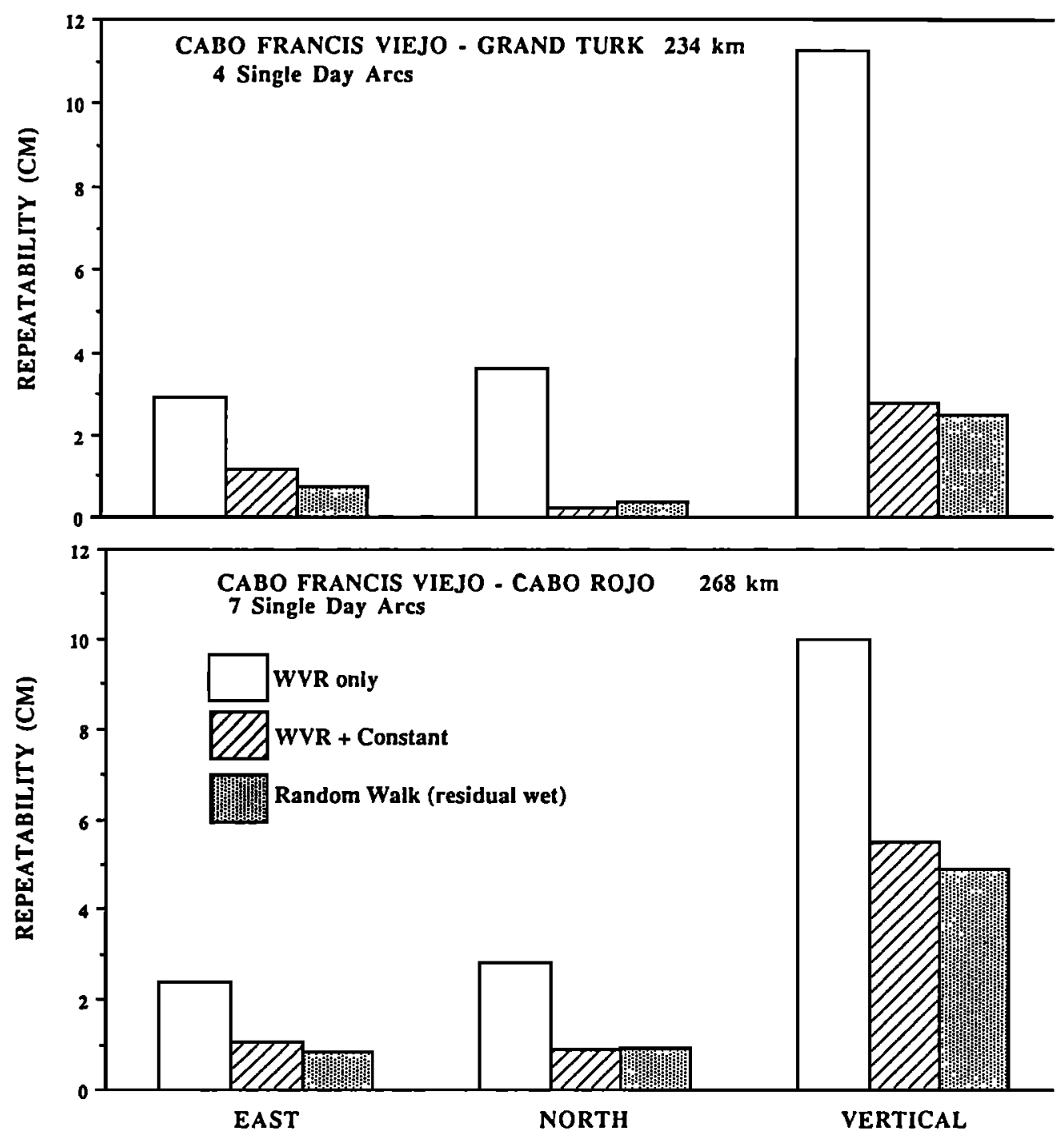

Fig. 6. Same as Figure 3, using bias-fixed baseline estimates.

solutions is that we were able to resolve biases on much longer baselines with the multiday arc approach. For example, with single-day arcs we were able to resolve less than $20 \%$ of the biases on baselines between 500 and $2000 \mathrm{~km}$ and none on longer baselines. With the multiday arcs, almost all the biases were resolved on baselines less than $1000 \mathrm{~km}$; more than $95 \%$ of the biases were resolved for Hat Creek-Fort Davis $(-2000 \mathrm{~km})$ and more than $60 \%$ of the biases were resolved for Hat Creek-Haystack $(\sim 4000 \mathrm{~km})$. Figure 8 compares the single-day arc versus multiday arc results, resolving all biases to the extent possible for each approach. Note the improvement in repeatability of horizontal components for all five baselines longer than $800 \mathrm{~km}$ (in four cases by more than a factor of 2), and the improvement in the vertical component estimates for nine out of ten baselines longer than $300 \mathrm{~km}$. For baselines shorter than the values listed above, where presumably orbits are not the dominant error source, there was no significant difference between the single-day and multiday arc approach.

In the course of the multiday arc analysis, a stochastic model was tested for the GPS satellite solar radiation pressure coefficients. This model, described by Lichten and Bertiger [1989] and Lichten [1990b], allows for estimation of tightly constrained accelerations acting on the spacecraft in order to compensate for effects such as gas leaks and deficiencies in the solar pressure model which can build up over data arcs of several days or more. However, when applied to the 1986 Caribbean data set, no statistically significant improvement in baseline repeatability was noticed. We conclude that the error budget for orbits obtained with multiday arcs of 2-3 days without stochastic force models is dominated by other, nonforce errors, likely associated with residual tropospheric effects and geometric measurement strength.

\section{Precision and Accuracy}

One measure of the precision of our results is the root mean square (rms) scatter about the weighted mean (the repeatability; equation (15)) of the daily baseline estimates. Figure 9 plots repeatability of the horizontal and vertical components as a function of baseline length after optimum tropospheric calibration, bias fixing and multiday arc 


\section{ESTIMATION OF RESIDUAL WET DELAY TO WVR CALIBRATION VS ESTIMATION OF TOTAL WET DELAY}
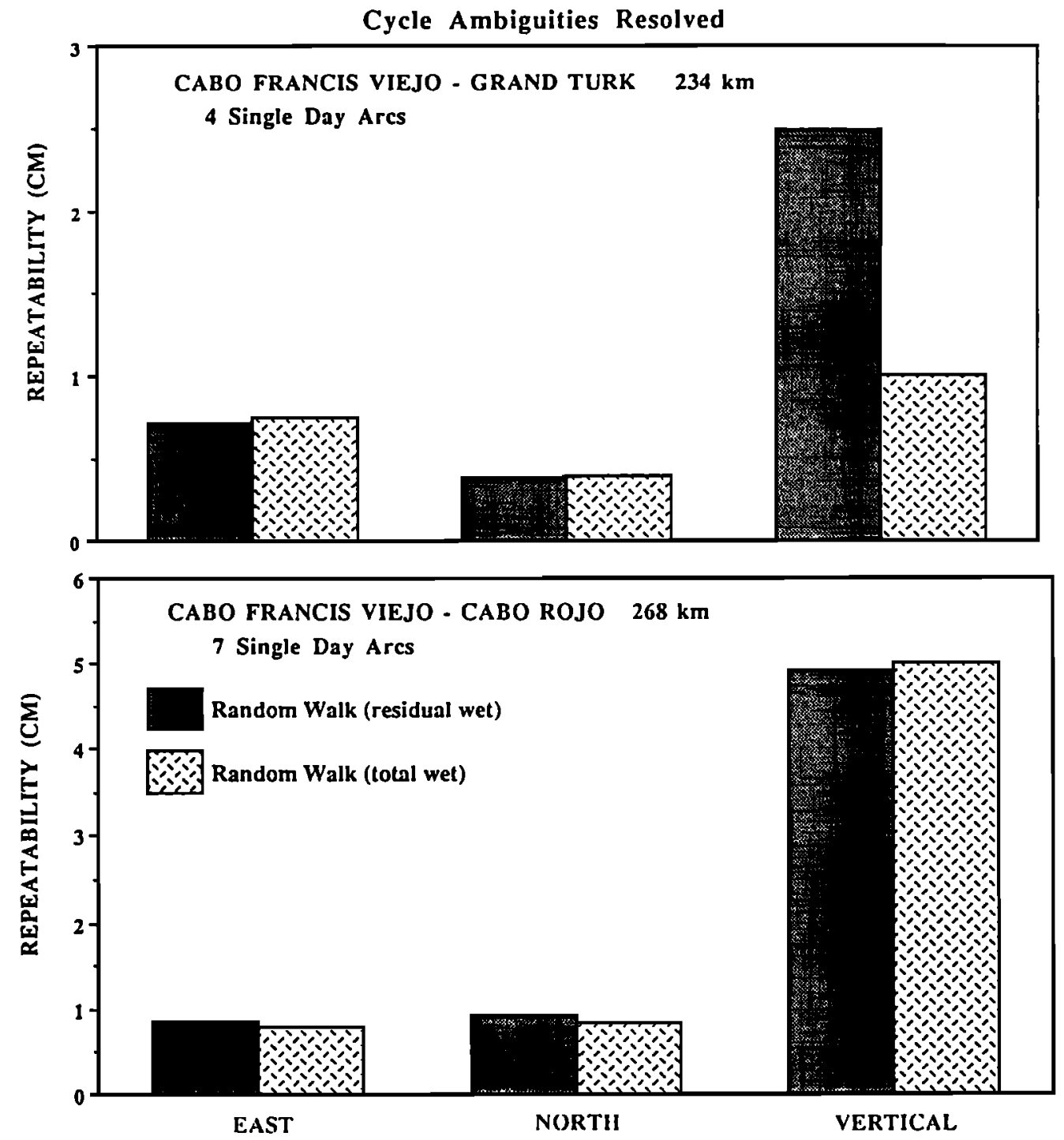

Fig. 7. Comparison of WVR-calibrated baseline estimates using a random walk residual error model (from Figure 6) with baseline estimates obtained without prior calibration, using a random walk model for the entire wet tropospheric path delay (Table 5).

estimation for all the Caribbean baselines. The standard deviation of baseline estimates as a function of baseline length can be described by [Savage and Prescott, 1973]

$$
\sigma_{x}=\left(a^{2}+b^{2} L^{2}\right)^{1 / 2}
$$

where $\sigma_{x}$ is the standard deviation of component $x$ (east, north or vertical), $L$ is baseline length, and $a$ and $b$ are coefficients determined by the technique. For the range of baseline lengths defined by our network, the value $a$ reflects mainly data noise and tropospheric errors, dominant at shorter baseline lengths, while $b$ reflects mainly orbit errors, dominant at longer baseline lengths. Figure 9 also shows best fit curves of this form through the repeatability data. For the horizontal components, $a$ is $6.7 \mathrm{~mm}$ (east) and $7.6 \mathrm{~mm}$ (north), and $b$ is $1.26 \times 10^{-8}$ (east) and $3.0 \times 10^{-9}$ (north). The vertical component, after multiday arc analysis, does not depend on baseline length, so the above error model is not particularly useful; a best fit curve of this form is a horizontal line $\left(b<1 \times 10^{-9}\right)$, with intercept $a$ given by the average of the repeatability values, $4.7 \mathrm{~cm}$. This probably reflects the influence of tropospheric calibration errors on the vertical component estimates, which over this range of lengths do not depend strongly on baseline length. The coefficient $b$ in equation (16) is a good indicator of the effect of the multiday arc approach in reducing orbit-related errors. Best fit curves through the single-day arc results gave $b=$ $2.8 \times 10^{-8}$ (east), $2.4 \times 10^{-8}$ (north) and $5.6 \times 10^{-8}$ (vertical), indicating more than a factor of 2 improvement in the average repeatability of long baseline estimates with multiday arcs.

The repeatability obtained in this first northern Caribbean experiment compares favorably to that obtained in the southwestern United States [Dong and Bock, 1989; Blewitt, 1989; Dixon et al., 1990], where proximal fiducial stations 


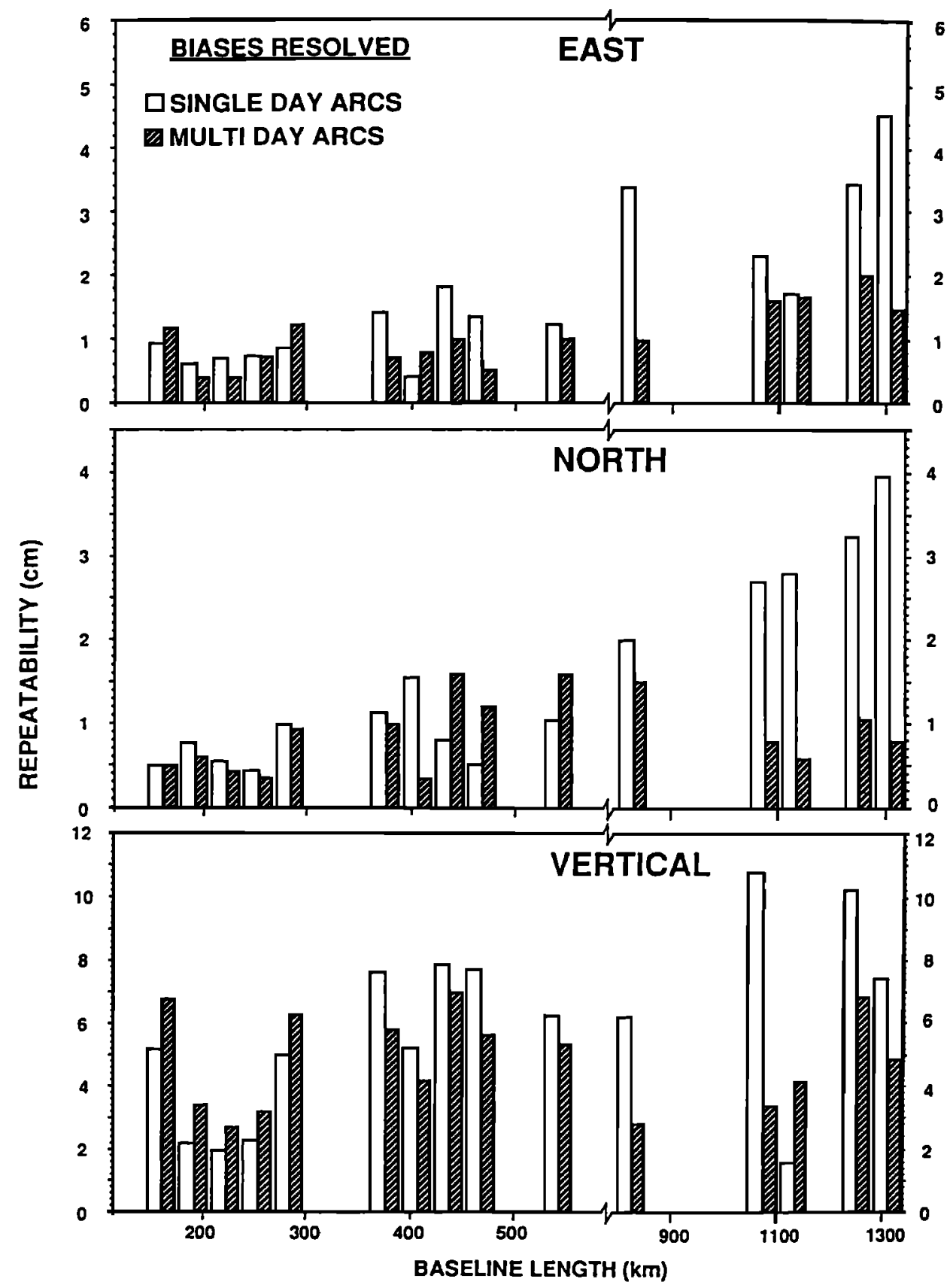

Fig. 8. Similar to Figure 4, comparing single-day and multiday orbital arcs, using optimized tropospheric treatment (Table 5) and resolving all carrier phase biases to the extent possible for both approaches. Note improvement in longer baseline estimates with multiday arcs.

are available and wet tropospheric path delays and path delay variability (and presumably wet path delay calibration errors) are usually considerably less. For example, Dixon et al. [1990] report $a=5 \mathrm{~mm}$ (east) and $4 \mathrm{~mm}$ (north), b = $2.2 \times 10^{-8}$ (east) and $<1 \times 10^{-9}$ (north), and average vertical component repeatability of $2.9 \mathrm{~cm}$, based on analysis of 19 baselines between 35 and $620 \mathrm{~km}$, mainly located in southern California, for an experiment conducted in 1986. The overall similarity in short-term repeatability for these Caribbean and southem California GPS experiments leads us to conclude that the strategies described here for dealing with orbit and troposphere-related errors in the Caribbean region were adequate. Nevertheless, small differences between the two data sets give clues to the remaining dominant error source in the Caribbean GPS results. The average vertical repeatability is worse in the Caribbean case relative to the southern California results. This component is particularly sensitive to tropospheric calibration error because of correlation with the zenith atmospheric delay [Herring, 1986]. Sensitivity analyses for GPS in the Caribbean region conducted prior to this experiment quantified the importance of tropospheric calibration to accurate vertical component estimates [Kroger et al., 1986]. The difference in average vertical repeatability between the southern California and northern Caribbean examples is small considering the small sample size and data scatter. Nevertheless, the comparison 


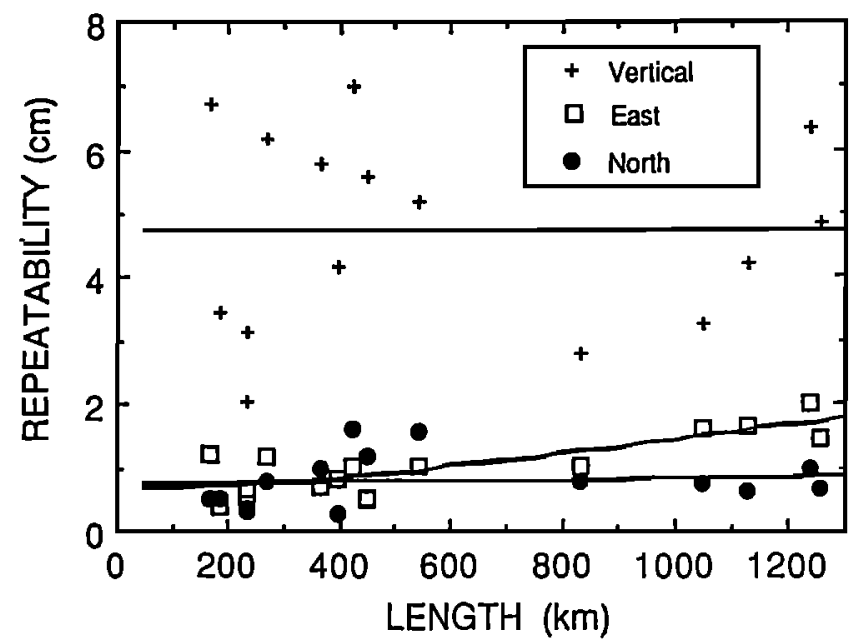

Fig. 9. Baseline repeatability (rms scatter about the weighted mean; equation [15]) after optimum troposphere treatment (Table 5), multiday arcs and bias fixing. Best fit curves through each component of the form $\left(a^{2}+b^{2} L^{2}\right)^{1 / 2}$ (equation [16], text) where $L$ is baseline length, have coefficients $a=6.7 \mathrm{~mm}$ (east), $7.6 \mathrm{~mm}$ (north) and $4.7 \mathrm{~cm}$ (vertical) and $b=1.3 \times 10^{-8}$ (east), $3 \times 10^{-9}$ (north) and $<1 \times 10^{-9}$ (vertical).

suggests the possibility that improved tropospheric calibration could improve the precision of vertical component estimates in the Caribbean region, and presumably other regions of high wet tropospheric path delay and variability.

Baseline repeatability for the 6-8 days of data available from this experiment primarily reflects random error sources whose effects may be reduced by averaging over several days of observations, and is one measure of precision. It is not possible at this time to assess in any rigorous way the longer term precision or accuracy of these baseline estimates, because independent measurements are not available for comparison in the Caribbean region. However, there are indirect methods to assess accuracy, primarily based on GPS-VLBI comparisons in other regions. In the following discussion we will use the term "accuracy" to describe the results of those comparisons, recognizing the limitations to this approach [Dixon et al., 1990].

First, comparisons with VLBI-determined baselines in the United States occupied with GPS during the Caribbean experiment and analyzed simultaneously with Caribbean data provide some guide. GPS results for the $987-\mathrm{km}$ Monument Peak to Hat Creek baseline are representative, and are shown in Figure 10 along with the mean VLBI estimate. The deviation of the mean GPS estimate from the corresponding mean VLBI estimate $(1.1 \mathrm{~cm}$ east, $0.1 \mathrm{~cm}$ north, $5.2 \mathrm{~cm}$ vertical) is consistent with the day-to-day repeatability, suggesting no major difference between precision (defined by day-to-day repeatability) and accuracy (defined by VLBI comparison). Second, we can look at the relation between short-term GPS repeatability and accuracy (again defined by VLBI comparison) achieved in other GPS experiments, principally in southern California. These data also suggest that short term repeatability and accuracy of GPS baseline estimates may be comparable, provided robust fiducial networks are available and carrier phase cycle ambiguities are resolved. In such cases, GPS horizontal baseline component estimates appear to be accurate at a level of about $5 \mathrm{~mm}$ plus 1-2 parts in $10^{8}$ of baseline length [Dong and Bock, 1989; Blewitt, 1989; Dixon et al., 1990].
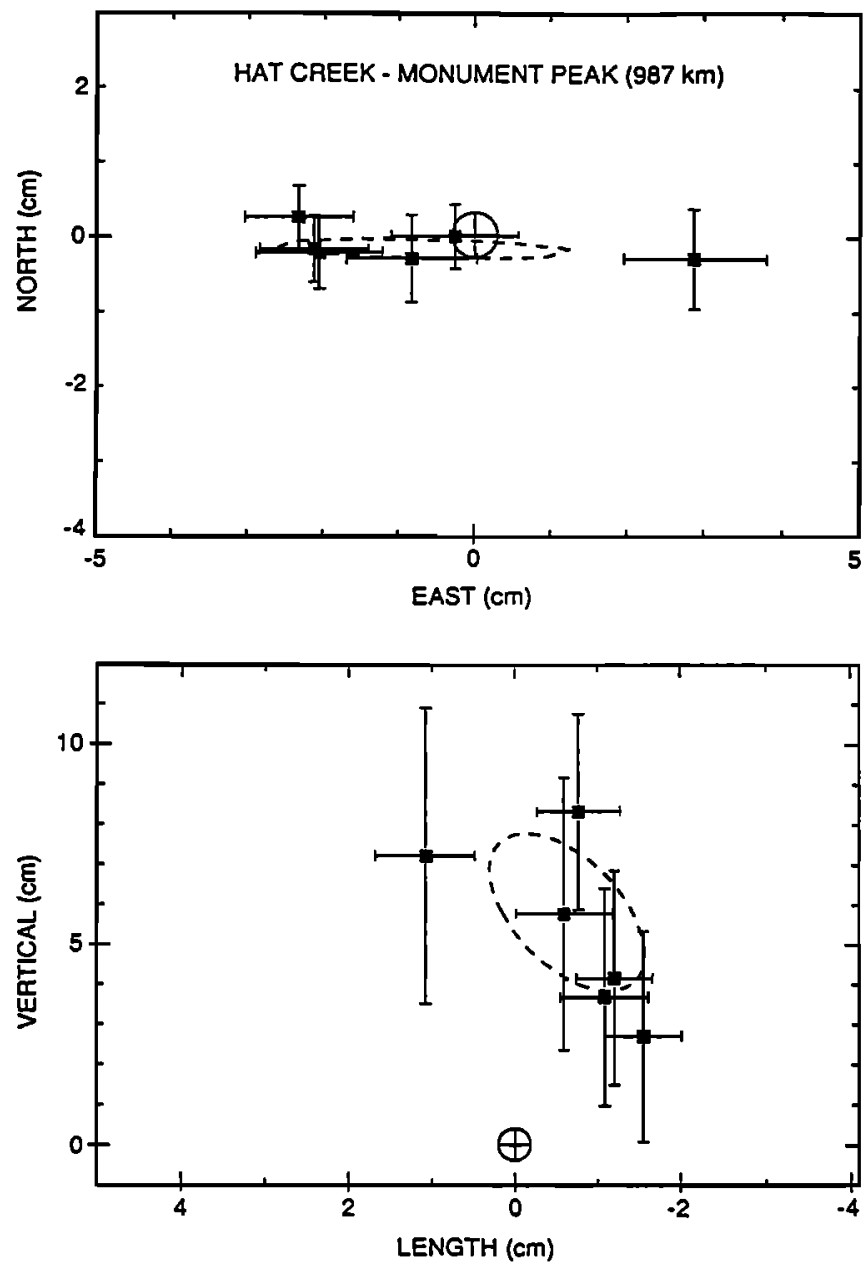

Fig. 10. Comparison of mean VLBI estimate (crossed circle at coordinates 0,0 ) and 6 daily GPS estimates for the Monument Peak to Hat Creek baseline $(987 \mathrm{~km})$ obtained during the June 1986 Caribbean experiment. The 1o error ellipse for the GPS estimates is also shown. The offsets between the mean GPS and mean VLI estimates are $1.1 \mathrm{~cm}$ (east), $0.1 \mathrm{~cm}$ (north) and $5.2 \mathrm{~cm}$ (vertical). VLBI solution GLB 223 mapped to June 1986 epoch, from J. W. Ryan, C. Ma and E. Himwich (Goddard Space Flight Center, written communication, 1988).

Short-term repeatability may not be a valid indicator of performance if systematic errors are present that do not affect results over the short (several day) observation periods typical of most GPS experiments [Davis et al., 1989]. Nevertheless, the agreement between GPS and VLBI generally observed is not likely fortuitous. Preliminary data over 3 years on a few baselines in southern California suggest that longer term repeatability is similar to short-term repeatability when robust fiducial networks are employed and carrier phase cycle ambiguities are resolved, again suggesting that accuracy is not significantly worse than short-term repeatability for properly configured experiments [Larson, 1990; Dixon et al., 1990].

Additional considerations for evaluating longer term GPS performance in the Caribbean and elsewhere include ionospheric effects and systematic errors in fiducial station location. Ionospheric activity was low in the period 1986-1988, the time span for most of the GPS-VLBI comparison data mentioned above. Ionospheric activity may impact, among other things, the ability to resolve the cycle ambiguities, 
and thus could be a greater source of error in the future. Fiducial errors would not greatly affect day-to-day repeatability given the near-constant satellite geometry during the 8 days of the 1986 experiment (or most individual GPS experiments) but could systematically bias results and thus affect longer term comparisons. Moreover, the affect of these errors might be smaller in California (the main source for GPS-VLBI comparison data available to us) relative to the Caribbean region, because the Califomia GPS networks are closer to the fiducial sites and hence less sensitive to fiducial errors. Sensitivity analyses confirm that fiducial station mislocation is the largest source of systematic error so far identified for high precision GPS geodetic measurements in the Caribbean.

We have attempted to quantify this effect with the following empirical test. Since we have a total of seven continental U.S. sites that can potentially act as fiducial sites, but only three are required for orbit control, it is possible to process the data with different (sometimes nonoptimum) combinations of fiducial stations. We reprocessed all the Caribbean data using the optimum troposphere model, multiday arc, bias-fixed approach described previously, with the following five combinations of fiducial network: (1) Hat Creek, Fort Davis, Haystack; (2) Hat Creek, Richmond, Haystack; (3) Monument Peak, Richmond, Haystack; (4) Fort Davis, Richmond, Haystack; (5) Hat Creek, Fort Davis, Richmond, Haystack. These combinations resulted in five different estimates for the various Caribbean baselines, and their scatter is a measure of the sensitivity of the baseline estimates to fiducial station mislocation. We also believe this to be a conservative estimate, inasmuch as some of the combinations have nonoptimum geometry and would not likely be employed in subsequent experiments. The rms scatter of the five different estimates of each Caribbean baseline is shown in Figure 11 . Since this quantity primarily reflects fiducial error which maps into orbit error, we expect the corresponding baseline error to be a linear function of baseline length with zero intercept, and thus have fit these data with straight lines rather than the curve described by equation (16). For both horizontal components, this "fiducial error" is less than $1 \mathrm{~mm}$ plus 7 parts in $10^{8}$ of baseline length. For the vertical component, this error is less than $2 \mathrm{~mm}$ plus 2 parts in $10^{8}$ of baseline length. These values are less than the error level described
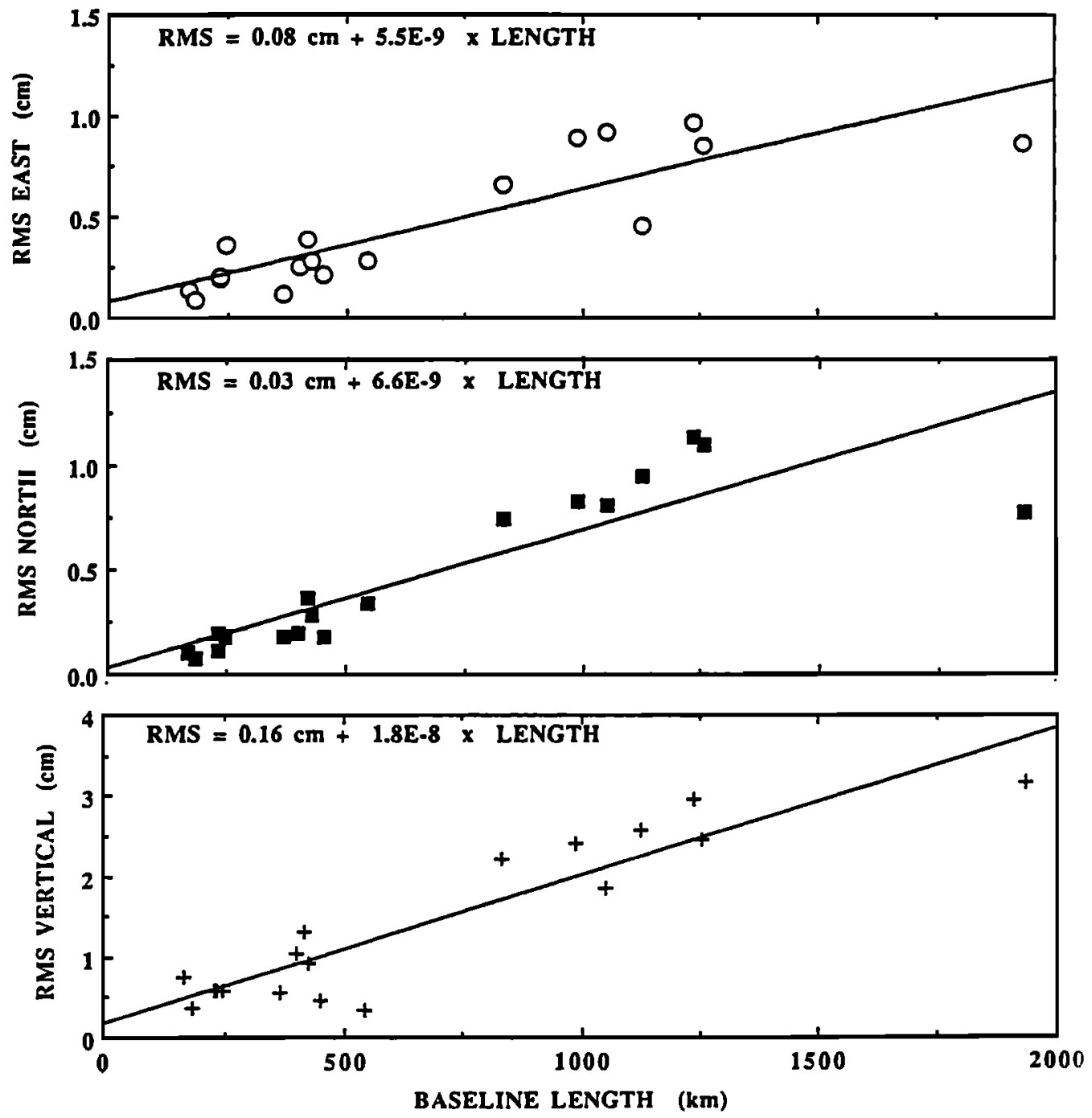

Fig. 11. Unweighted rms scatter of Caribbean baseline estimates using five different fiducial networks (see text). Best fit lines are also shown. The rms scatter of these estimates is one measure of systematic error due to fiducial station mislocation. 
by repeatability (Figure 9) suggesting that systematic error in these estimates due to fiducial station mislocation is low compared to random error.

Obviously, additional occupations of the Caribbean network and continued comparisons to VLBI results in the United States and elsewhere will be required before the true, long-term level of performance for GPS geodesy in the region can be determined rigorously, but we find these initial results very encouraging.

\section{Discussion}

We have demonstrated that day-to-day repeatability better than $8 \mathrm{~mm}$ plus 1.3 parts in $10^{8}$ for the horizontal components of GPS baseline estimates can be achieved in the Caribbean region for baselines from 170 to $1260 \mathrm{~km}$ in length, despite high levels of tropospheric variability and lack of proximal fiducial sites. Assuming the arguments presented above on the relation between repeatability and accuracy are approximately correct, then the repeatability obtained in this first epoch GPS experiment in the Caribbean can be used as a rough guide to longer term GPS performance in the region. We can then evaluate the geologic problems that can be attacked with GPS, and the time span over which observations must be made to obtain useful results, provided we have some estimate of deformation rates in the region. We recognize that there may be some systematic errors not accounted for in our analyses (e.g., phase center variation due to use of different antennas in later experiments). To be somewhat conservative, we will arbitrarily assume that the measurement accuracy for a horizontal component of a GPS baseline vector is about a factor of 2 worse than the repeatability obtained in our final results (Figure 9) and can be described approximately by equation (16) with $a=1.5 \mathrm{~cm}$ and $b=2.5 \times 10^{-8}$. We will use this estimate of single measurement accuracy as a rough guide to estimate the time required to achieve a given accuracy in rate determination for several example geologic problems, described below.

Hispaniola is undergoing complex deformation and is a region of high seismic risk. Geodetic constraints on the nature, spatial distribution and rate of strain are important in understanding such deformation. Although the main part of the plate boundary may be submarine and lies north of the island (the Oriente fracture zone; Figure 1), maps of recent seismicity show almost as much seismic activity on the island itself and in the San Pedro Basin to the south [e.g., Bowin, 1975; Schell and Tarr, 1978; Sykes et al., 1982; Byrne et al., 1985]. Magnitude 7 events are fairly common, and magnitude 8 events are known from historical records [e.g., Kelleher et al., 1973; Sykes et al., 1982]. A magnitude 8.1 event ruptured the northeast coast of Hispaniola in 1946. Other evidence for active tectonics on Hispaniola includes high topography and large gravity anomalies [Bowin, 1975], deformation of Pliocene to Quaternary sediments [Ladd et al., 1981; Biju-Duval et al., 1982], raised Pleistocene reefs [Dodge et al., 1983] and numerous faults with Neogene to Recent offsets [e.g., Dixon and Daily, 1981; Mann et al., 1984]. Geodetic networks designed to monitor block tectonics within this complex plate boundary zone will involve fairly dense networks, ideally with site spacing less than $100 \mathrm{~km}$ (Figure 1). Rates of motion on the major strike-slip faults in Hispaniola, the Camu, Septentrional, South Samana Bay and Enriquillo fault zones (Figure 1) are essentially unknown, although they are all likely to be less than $10 \mathrm{~mm} / \mathrm{yr}$, based on the overall plate motion rate $(-20 \mathrm{~mm} / \mathrm{yr}$; Stein et al., [1988]; $\sim 12$ $\mathrm{mm} / \mathrm{yr}$; DeMets et al., [1990]). Recent work on the Septentrional fault suggests the possibility of relatively fast $(10-20 \mathrm{~mm} / \mathrm{yr})$ motion at certain times in the last $10 \mathrm{Ma}$ [Winslow et al., 1990]. Geodetic determination of the modern rate of motion on these faults is important, preferably to an accuracy better than $2-3 \mathrm{~mm} / \mathrm{yr}$.

The relative azimuth of plate motion between North America and the Caribbean is also of interest. For example, it is possible that the North American and Caribbean plates are slowly converging along part of their common boundary, based on observed compressional deformation in Hispaniola, thrust solutions for earthquakes and plate reconstructions [Ladd, 1976; Pindell and Dewey, 1982]. Mann et al [1984] explained compressional deformation and uplift in Hispaniola as the result of a transpressional westnorthwest bend in an otherwise east-west plate boundary. The Enriquillo fault zone is considered to be an east-west trending, strike-slip parallel "bypass" fault, formed in the Pliocene in response to the restraining bend [Mann et al, 1984]. However, compressional deformation occurring well south of this fault zone is more difficult to explain with this model. Deformed recent sediments and thrust focal mechanisms for earthquakes in the Muertos Trough south of Hispaniola [Ladd et al., 1981; Kafka and Weidner, 1979] (Figure 1) might reflect oblique convergence. Convergence of a few millimeters per year, below the resolution of current global models, could explain these observations, and is important for interpreting geologic structures and evaluating seismic risk. Altemately, some of the observations in and near Hispaniola could be explained by a block rotation model. Discriminating among these possibilities with GPS would require very high accuracy measurements, capable of resolving rates to a few millimeters per year or better.

Stein et al. [1988] determined the North AmericaCaribbean relative motion rate to be about $20 \pm 5 \mathrm{~mm} / \mathrm{yr}$. With additional data and different assumptions about the location of a possible North America-South America plate boundary, Demets et al. [1990] determined a North AmericaCaribbean rate of $12 \pm 3 \mathrm{~mm} / \mathrm{yr}$. Rosencrantz et al. [1988] determined motion at the Cayman spreading center to be $15 \pm 5 \mathrm{~mm} / \mathrm{yr}$. Independent geodetic tests of this rate would therefore be most useful if they were accurate at the 3-5 $\mathrm{mm} / \mathrm{yr}$ level.

The uncertainty in the rate component of a plate motion vector, $\sigma_{r}$, can be estimated from the relation [Coates et al., 1985]:

$$
\sigma_{r}=\frac{\sigma_{m}}{T}\left[\frac{12 T / \Delta t}{(1+T / \Delta t)(2+T / \Delta t)}\right]^{1 / 2}
$$

where $\sigma_{m}$ here represents the total measurement uncertainty (accuracy), $\Delta t$ is the time between measurements (assumed constant), and $T$ is the total time span of observations. Ignoring possible slowly varying systematic errors that we are currently unaware of, $\sigma_{m}$ will be about $1.5 \mathrm{~cm}$ for a 100 $\mathrm{km}$ baseline, based on our previous arguments concerning repeatability and accuracy. This is an appropriate length for measurement of regional deformation. For $\Delta t=3$ years, the total time to achieve a rate uncertainty better than $5 \mathrm{~mm} / \mathrm{yr}$ is 6 years (three experiments). For a rate uncertainty better than $2 \mathrm{~mm} / \mathrm{yr}$, the corresponding time span is 12 years (five experiments). The overall plate motion rate can be measured by baselines of about $500 \mathrm{~km}$ in length (provided that block 
rotations are not occurring). For $\sigma_{m}=2 \mathrm{~cm}$ on a $500-\mathrm{km}$ baseline, $\sigma_{r} \approx 5 \mathrm{~mm} / \mathrm{yr}$ after 6 years of measurements taken every 3 years (three experiments) and will be better than 2 $\mathrm{mm} / \mathrm{yr}$ after 15 years (six experiments).

Several factors appear to be important in maximizing the accuracy of GPS measurements, and should be considered for future GPS experiment design in this and similar regions. First, a minimum amount of data is obviously required to achieve optimum baseline estimates. Sites with less than 100 "compressed" (6-min averaged) data points yielded high formal errors and correspondingly poor baseline estimates. Assuming an adequate satellite constellation and a four-satellite receiver, and allowing for mutual visibility with U.S. fiducial sites, this quantity of data can be collected in about 4 hours of observation. At least three such observation periods would provide some check on measurement repeatability. This currently requires 3 days of observation, but the required time will decrease as additional satellites become available. Second, four or more geographically separated VLBI sites in the United States appear to provide an adequate fiducial network with some redundancy, and ensure that orbit-related errors are not the dominant error source for most baselines in the network. Third, adequate characterization of the wet tropospheric path delay is important. We have demonstrated that stochastic modeling of the entire wet delay coupled with estimation techniques is a viable approach, but at least one high-accuracy WVR in the region would provide some independent verification of the validity of a particular stochastic model. It does not appear to be critical to have WVRs deployed at all sites given the current accuracy of GPS and WVR systems. Finally, a sufficiently dense network of sites within the Caribbean is required to ensure carrier phase cycle ambiguity resolution. The relatively sparse network used in the 1986 experiment would be adequate under similar conditions. However, ionospheric activity was low in 1986; this was probably helpful in initial resolution of the carrier phase biases on the shortest $(168,184 \mathrm{~km})$ baselines in our sparse network. For future experiments, several additional sites defining shorter baselines might ensure resolution of the phase biases even in the presence of a more active ionosphere, and would better describe the complex deformation in the region.

\section{CONCLUSIONS}

For the June 1986 Caribbean GPS experiment, baseline estimates using calibration of the wet troposphere based on surface meteorological measurements and a simple atmospheric model did not achieve the repeatability of estimates employing water vapor radiometer measurements. Stochastic estimation of the entire wet delay using the GPS data directly yielded repeatability comparable to that obtained with WVR calibration, suggesting that stochastic estimation of the wet delay is an acceptable alternative to WVR calibrations of the type and quality available from this experiment. Calibration errors in the WVRs generally appear to be constant or near constant biases, implying that the WVRs correctly measured temporal fluctuations of the wet tropospheric path delay. Given the high wet path delay and high variability encountered in this experiment, optimum tropospheric calibration was required before carrier phase cycle ambiguity resolution (bias fixing) was possible. After tropospheric effects were corrected, bias fixing was possible for baselines shorter than about $550 \mathrm{~km}$ with single-day orbital arcs, and improved the repeatability of the horizontal component estimates by about a factor of 2 .
Multiday orbital arc analysis enabled bias fixing on baselines exceeding $1000 \mathrm{~km}$ in length.

Four-five distributed VLBI sites in the United States provide adequate satellite tracking capability for high-precision geodesy in the northem Caribbean region with some redundancy.

The day-to-day repeatability achieved in the first GPS experiment in the northern Caribbean was better than $8 \mathrm{~mm}$ plus 1.3 parts in $10^{8}$ of baseline length for horizontal components. Several heuristic arguments suggest that the accuracy of the measurements is not significantly worse than the repeatability. This level of performance should enable useful constraints on plate boundary zone deformation and overall plate motion within 10 and 15 years, respectively.

Acknowledgments. We thank C. Vegos, M. Golombek, S. Dinardo, R. Bilham, C. Rocken, M. Janssen and G. Foulger for collecting the GPS and WVR data for this experiment. Numerous groups contributed additional personnel and equipment, including UNAVCO, the U.S. Geological Survey, the National Geodetic Survey, the Inter-American Geodetic Survey, and the Texas Department of Highways and Public Transportation. We are also indebted to Mineria and the Instituto Cartografico Militar (Dominican Republic), the Govemor's Office and Chief Surveyor's Office (Turks and Caicos Islands), and to personnel at the Guantanamo Naval Station and the University of Puerto Rico. C. Bowin, E. Hemandez, M. Golombek, J. Gotay, J. Joyce, C. J. Tumer, and R. Robinson assisted in site selection and preparation. We also thank the GIPSY team for numerous contributions, especially G. Blewitt for leading us through the ambiguities of bias fixing and $D$. Tralli for advice on troposphere models. Gerhard Beutler, Seth Stein and an anonymous reviewer suggested numerous improvements to the text. This research was conducted at the Jet Propulsion Laboratory, California Institute of Technology under contract to the National Aeronautics and Space Administration.

\section{REFERENCES}

Allan, D. W., Statistics of atomic frequency standards, Proc. IEEE, 54, 221-230, 1966.

Beutler, G., I. Bauerisma, W. Gurtner, M. Rothacher, and T. Schildknecht, Evaluation of the 1984 Alaska Global Positioning System campaign with the Bemese GPS software, J. Geophys. Res., 92, 1295-1303, 1987.

Bierman, G. J., Factorization Methods for Discrete Sequential Estimation, 241 pp., Academic Press, Orlando, Florida, 1977.

Biju-Duval, B., G. Bizon, A. Mascle, and C. Muller, Active margin process: Field observations in Southem Hispaniola, Am. Assoc. Pet. Geol. Mem., 34, 325-344, 1982.

Blewitt, G., Carrier phase ambiguity resolution for the Global Positioning System applied to geodetic baseline up to $2000 \mathrm{~km}$, J. Geophys. Res., 94, 10187-10203, 1989.

Bowin, C., The geology of Hispaniola, in The Ocean Basins and Margins, Vol. 3, edited by A. E. M. Naim and F. G. Stehli, pp. 501-552, Plenum, New York, 1975.

Burke, K., J. Grippi, and A. M. C. Sengor, Neogene structures in Jamaica and the tectonic style of the northem Caribbean plate boundary, J. Geol., 88, 375-386, 1980.

Burke, K., C. Cooper, J. F. Dewey, P. Mann, and J. L. Pindell, Caribbean tectonics and relative motions, in The Caribbean-South America Plate Boundary and Regional Tectonics, edited by W. E. Bonini, R. B. Hargraves, and R. Shagan, pp. 31-63, Geological Society of America, Boulder, Colo., 1984.

Byme, D. B., G. Suarez, and W. R. McCann, Muertos Trough subduction microplate tectonics in the northem Caribbean, Nature, 317, 420-421, 1985.

Chao, C. C., The troposphere calibration model for Mariner Mars 1971, Tech. Rep. 32-1587, pp. 61-76, Jet Propul. Lab., Pasadena, Calif., 1974

Coates, R. J., H. Frey, G. D. Mead, and J. M. Bosworth, Space age geodesy: The NASA Crustal Dynamics Project, IEEE Trans. Geosci. Remote Sens., GE-23, 360-368, 1985. 
Davis, J. L., T. A. Herring, I. I. Shapiro, A. E. E. Rogers, and G. Elgered, Geodesy by radio interferometry: Effects of atmospheric modelling errors on estimates of baseline length, Radio Sci. 20. 1593-1607, 1985.

Davis, J. L., W. H. Prescott, J. L. Svarc, and K. Wendt, Assessment of Global Positioning System measurements for studies of crustal deformation, J. Geophys. Res., 94, 13635-13650, 1989.

Demets, C., R. G. Gordon, D. F. Argus, and S. Stein, Current plate motions, Geophys. J. Int., 101, 425-478, 1990.

Dixon, T. H., and M. I. Daily, Analysis of a SEASAT/SAR image of northeast Dominican Republic, Photo-Interpretation, 5(F-4), 4147, 1981 .

Dixon, T. H. and S. Komreich Wolf, Some tests of wet tropospheric calibration for the CASA Uno Global Positioning System experiment, Geophys. Res. Lett., 17, 203-206, 1990.

Dixon, T. H., M. Golombek, and C. L. Thomton, Constraints on Pacific Plate kinematics and dynamics with Global Positioning System measurements, IEEE Trans. Geosci. Remote Sens., GE-23, 491-501, 1985.

Dixon, T., G. Blewitt, K. Larson, D. Agnew, B. Hager, P. Kroger, L. Skrumeda, and W. Strange, The June 1986 GPS experiment in Southem California, EoS Trans. AGU, 71, 1051-1056, 1990.

Dodge, R. E., R. G. Fairbanks, L. K. Benninger, and F. Maurasse, Pleistocene sea levels from raised coral reefs in Haiti, Science, 219, 1423-1425, 1983.

Dong, D., and Y. Bock, Global Positioning System network analysis with phase ambiguity resolution applied to crustal deformation studies in California, J. Geophys. Res., 94, 39493966, 1989.

Elgered, G., J. L. Davis, T. A. Herring, and I. I. Shapiro, Geodesy by radio interferometry: Water vapor radiometry for estimation of the wet delay, J. Geophys. Res., in press, 1990.

Freymueller, J. T., and M. P. Golombek, Geometry and treatment of fiducial networks: Effect on GPS baseline precision in South America, Geophys. Res. Lett., 15, 1467-1471, 1988.

Gary, B. L., S. J. Keihm, and M. A. Janssen, Optimum strategies and performance for the remote sensing of path delay using groundbased microwave radiometers, IEEE Trans. Geosci. Remote Sens. GE-23, 479-484, 1985.

Herring, T. A., Precision of vertical position estimates from very long baseline interferometry, J. Geophys. Res., 91, 9177-9182, 1986.

Janssen, M. A., A new instrument for determination of radio path delay due to atmospheric water vapor, IEEE Trans. Geosci. Remote Sens., GE-23, 485-490, 1985.

Jordan, T. H., The present-day motions of the Caribbean plate, $J$. Geophys. Res., 80, 4433-4439, 1975.

Kafka, A. L., and D. J. Weidner, The focal mechanisms and depths of small earthquakes as determined from Raleigh-wave radiation pattems, Bull. Seismol. Soc. Am., 69, 1379-1390, 1979.

Kelleher, J. A., L. Sykes, and J. Oliver, Possible criteria for predicting earthquake locations and their application to major plate boundaries of the Pacific and the Caribbean, J. Geophys. Res., 78, 2547-2585, 1973.

Kroger, P. M., J. M. Davidson, and E. C. Gardner, Mobile very long baseline interferometry and Global Positioning System measurement of vertical crustal motion, J. Geophys. Res., 91, 91699176, 1986.

Ladd, J. W., Relative motion of South America with respect to North America and Caribbean tectonics, Geol. Soc. Am. Bull., 87, 969976, 1976.

Ladd, J. W., T. C. Shih, and C. J. Tsai, Cenozoic tectonics of central Hispaniola and adjacent Caribbean Sea, Am. Assoc. Pet. Geol. Bull., 65, 466-489, 1981.

Lanyi, G. E., Tropospheric delay effects in radio interferometry, Telecommun. Data Acquis. Prog. Rep. 42-78, pp. 152-159, Jet. Propul. Lab., Pasadena, Calif., April-June, 1984.
Larson, K., Application of GPS to measuring tectonic deformation in California, Ph.D. thesis, Univ. Calif., San Diego, 1990.

Lichten, S. M., Estimation and filtering for high-precision GPS positioning applications, Man. Geod., 15, 159-176, 1990a.

Lichten, S. M., Towards orbit accuracies of tens of $\mathrm{cm}$, Geophys. Res. Lett., 17, 205-218, 1990 b.

Lichten, S. M., and W. I. Bertiger, Demonstration of sub-meter GPS orbit determination and 1.5 parts in $10^{8}$ three dimensional baseline accuracy, Bull. Geod., 63, 167-189, 1989.

Lichten, S. M., and J. S. Border, Strategies for high-precision Global Positioning System orbit determination, J. Geophys. Res., 92, 12751-12762, 1987.

Mann, P., K. Burke, and T. Matumoto, Neotectonics of Hispaniola: Plate motion, sedimentation, and seismicity at a restraining band, Earth Planet. Sci. Lett., 70, 311-324, 1984.

Pindell, J., and J. F. Dewey, Permo-Triassic reconstruction of western Pangea and the evolution of the Gulf of Mexico/Caribbean region, Tectonics, 1, 179-211, 1982.

Remondi, B. W., Global Positioning System carrier phase: Description and use, Bull. Geod., 59, 361-377, 1985.

Robinson, S. E., The profile algorithm for microwave delay estimation from water vapor radiometer data, Radio Sci., 23, 401408, 1988.

Rosencrantz, E., M. Ross, and J. Sclater, Age and spreading history of the Cayman trough as determined from depth, heat flow, and magnetic anomalies, J. Geophys. Res., 93, 2141-2157, 1988.

Savage, J. C., and W. H. Prescott, Precision of Geodolite distance measurements, J. Geophys. Res., 78, 6001-6007, 1973.

Schell, B. A., and A. C. Tarr, Plate tectonics of the northeastem Caribbean Sea region, Geol. Minjbouw, 57, 319-324, 1978.

Sovers, O. J., and J. S. Border, Observation model and parameter partials for the JPL geodetic GPS modelling software "GPSOMC," Publ. 87-21, Rev. 1, 37 pp, Jet Propul. Lab., Pasadena, Calif., 1988.

Stein, S., C. Demets, R. Gordon, J. Brodholt, D. Argus, J. Engeln, P. Lundgren, C. Stein, D. Wiens, and D. Woods, A test of altemative Caribbean plate motion models, J. Geophys. Res., 93, 3041-3050, 1988.

Sykes, C. R., W. R. McCann, and A. L. Kafka, Motion of Caribbean plate during last 7 million years and implications for earlier Cenozoic movements, J. Geophys. Res., 87, 10656-10676, 1982.

Thompson, A. R., J. M. Moran, and G. W. Swenson, Interferometry and Synthesis in Radio Astronomy, John Wiley, New York, 1986.

Tralli, D. M., and S. M. Lichten, Stochastic estimation of tropospheric path delays in Global Positioning System geodetic measurements, Bull. Geod., 64, 127-159, 1990.

Tralli, D. M., T. H. Dixon, and S. Stephens, The effect of wet tropospheric path delays on estimation of geodetic baselines in the Gulf of Califomia using the Global Positioning System, $J$. Geophys. Res., 93, 6545-6557, 1988.

Treuhaft, R. N., and G. E. Lanyi, The effects of the dynamic wet troposphere on radio interferometric measurements, Radio Sci., 22, 251-265, 1987.

Winslow, M., et al., Tectonics of the San Francisco Ridge, northeast Dominican Republic, in Tectonics of Hispaniola, Geological Society of America, Boulder, Colo., in press, 1990.

T. H. Dixon, G. Gonzalez, S. M. Lichten, and E. Katsigris M/S 183-501, Jet Propulsion Laboratory, Califomia Institute of Technology, 4800 Oak Grove Drive, Pasadena, CA 91109.

(Received August 8, 1989; revised August 24, 1990; accepted September 6, 1990.) 